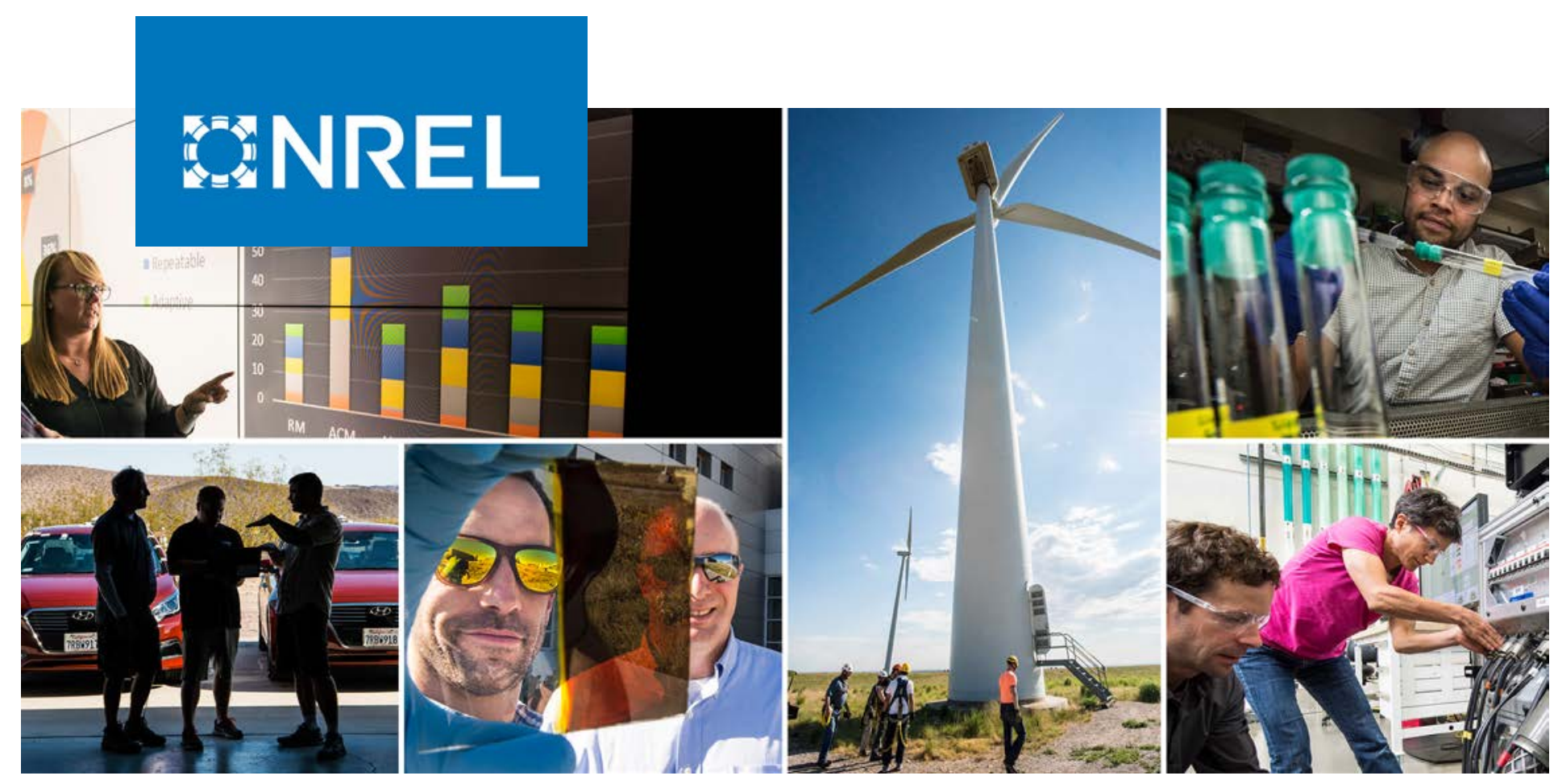

\title{
Operational Analysis of the Eastern Interconnection at Very High Renewable Penetrations
}

Joshua Novacheck, Greg Brinkman, and Gian Porro

National Renewable Energy Laboratory

NREL is a national laboratory of the U.S. Department of Energy

Office of Energy Efficiency \& Renewable Energy

Operated by the Alliance for Sustainable Energy, LLC

This report is available at no cost from the National Renewable Energy Laboratory (NREL) at www.nrel.gov/publications.
Technical Report

NREL/TP-6A20-71465

September 2018 


\title{
GNREL
}

\section{Operational Analysis of the Eastern Interconnection at Very High Renewable Penetrations}

\author{
Joshua Novacheck, Greg Brinkman, and Gian Porro
}

National Renewable Energy Laboratory

\section{Suggested Citation}

Novacheck, Joshua, Greg Brinkman, and Gian Porro. 2018. Operational Analysis of the Eastern Interconnection at Very High Renewable Penetrations. Golden, CO:

National Renewable Energy Laboratory. NREL/TP-6A20-71465.

https://www.nrel.gov/docs/fy18osti/71465.pdf.

NREL is a national laboratory of the U.S. Department of Energy Office of Energy Efficiency \& Renewable Energy Operated by the Alliance for Sustainable Energy, LLC

This report is available at no cost from the National Renewable Energy Laboratory (NREL) at www.nrel.gov/publications.

Contract No. DE-AC36-08GO28308
Technical Report

NREL/TP-6A20-71465

September 2018

National Renewable Energy Laboratory 15013 Denver West Parkway Golden, CO 80401

303-275-3000 • www.nrel.gov 


\section{NOTICE}

This work was authored by the National Renewable Energy Laboratory, operated by Alliance for Sustainable Energy, LLC, for the U.S. Department of Energy (DOE) under Contract No. DE-AC36-08G028308. Funding provided by the U.S. Department of Energy Office of Energy Efficiency and Renewable Energy Strategic Programs. The views expressed herein do not necessarily represent the views of the DOE or the U.S. Government.

This report is available at no cost from the National Renewable Energy Laboratory (NREL) at www.nrel.gov/publications.

U.S. Department of Energy (DOE) reports produced after 1991 and a growing number of pre-1991 documents are available free via www.OSTI.gov.

Cover Photos by Dennis Schroeder: (clockwise, left to right) NREL 51934, NREL 45897, NREL 42160, NREL 45891, NREL 48097, NREL 46526.

NREL prints on paper that contains recycled content. 


\section{Acknowledgments}

The authors thank the following people for providing substantive comments that informed the analysis and improved the structure and content of the report: Mark Ahlstrom, Doug Arent, Sam Baldwin, Aaron Bloom, Stephen Capanna, Paul Denholm, Gary Jordan, Ookie Ma, Larry Mansueti, Mike Meshek, David Mooney, Mark O’Malley. We also gratefully acknowledge funding for this work from the Office of Strategic Programs of the U.S. Department of Energy's Office of Energy Efficiency and Renewable Energy under contract number DE-AC36$08 G O 28308$. 


\section{Executive Summary}

The primary objective of the study reported here is to build on work by Mai et al. (2012) and Brinkman (2015) by performing detailed modeling of the U.S. Eastern Interconnection operations with approximately 70\% of all energy coming from wind and solar generation. The study assesses the ability to balance supply and demand for electricity using a unit commitment and economic dispatch model with a five-minute time resolution. In addition, the study explores the implications of different amounts of physical and institutional flexibility for balancing. We also present an analysis of system "stress" by quantifying various metrics, such as the amount of spare online capacity, penetration levels of non-synchronous generators, dayahead compared to real-time curtailment, and start-ups of peaking generation.

This study is not a comprehensive analysis of all aspects of operational reliability (including “essential reliability services” identified by the North American Electric Reliability Corporation) needed to ensure reliable production and delivery of electricity to the consumer. The analysis looks at relevant metrics, but it is not a rigorous analysis of voltage or frequency stability, black start, or other reliability needs. These aspects of high renewable generation scenarios should be studied in future work and build on previous studies, including Miller et al. (2014). In addition, this study focuses on operational costs of the power system, but previous and ongoing work has addressed the overall costs (capital and operational costs) of scenarios with high penetrations of renewable generation (Cole et al. 2017).

The work presented in this report represents one of the most detailed operational studies done at this penetration level, and it offers useful further insights into some aspects of how the Eastern Interconnection would need to operate under very high (above 70\%) annual amounts of wind and solar generation. Also, this work uses a novel method of geographic decomposition to perform the unit commitment and dispatch sequence.

\section{Scenarios}

This analysis studied two penetrations of renewable energy. The first penetration, called the Base-70\% scenario, achieved a renewable energy penetration of approximately $70 \%$ (after curtailment of variable renewable generation). The second penetration, called the Base-75\% scenario, increases potential variable generation (VG) energy by $10 \%$ and achieves approximately $75 \%$ penetration of renewable energy.

The Eastern Renewable Generation Integration Study (ERGIS) (Bloom et al. 2016) and the 80\% National Renewable Portfolio Standard (RPS) scenario from the NREL Standard Scenarios (Cole et al. 2017) informed the buildout of VG within the model for both penetrations. The modeled scenarios are not meant to be projections of future deployments of generation technologies or operating practices, but rather a possible geographic distribution of renewable generation technology deployments under the assumption that the regions collectively reach very high penetration levels. For reference, the U.S. Energy Information Administration's Annual Energy Outlook 2018 Reference case for the continental United States in 2050 is 31\% renewable energy generation. 
This study also considers three other scenarios using the VG penetrations from the Base-70\% scenario (see Table ES-1). Each of these scenarios restricts the operating flexibility of the power system to help understand how flexibility affects the system's ability to balance load and demand under high penetrations of VG.

Table ES-1. Scenarios Assessed in This Study

\begin{tabular}{lll}
\hline Scenario & $\begin{array}{l}\text { Renewable Generation } \\
\text { Portfolio }\end{array}$ & Assumptions \\
\hline Base-70\% & $\begin{array}{l}\text { Pre-curtailment energy } \\
\text { penetrations of } 47 \% \text { wind and } \\
27 \% \text { solar }\end{array}$ & Flexible operations \\
\hline Base-75\% & $\begin{array}{l}\text { Portfolio from Base-70\% with } \\
\text { VG increased by 10\% }\end{array}$ & Same as Base-70\% \\
\hline Must Run- & Same as Base-70\% & $\begin{array}{l}\text { 25\% of the coal and nuclear generation capacity } \\
\text { is assumed to be completely inflexible (e.g., a } \\
\text { must-run plant must be online and generating at } \\
\text { maximum capacity unless it has an outage) }\end{array}$ \\
\hline VG Limit-70\% & Same as Base-70\% & $\begin{array}{l}25 \% \text { of all regional load must be served by local } \\
\text { thermal or hydropower resources }\end{array}$ \\
\hline Hurdle Rate- & Same as Base-70\% & $\begin{array}{l}\text { \$10/MWh hurdle rate }{ }^{c} \text { between the market } \\
\text { regions in the day-ahead and real-time } \\
\text { simulations to represent friction and inefficiencies } \\
\text { that exist between system operators }\end{array}$ \\
\hline
\end{tabular}

${ }^{a}$ As in ERGIS, $40 \%$ of all photovoltaic (PV) capacity was modeled as distributed rooftop PV. The profile and capacity factor for these sites are representative of south-facing systems at a tilt of 15 degrees. The impacts on the distribution network are not analyzed in this study.

${ }^{b}$ Coal and nuclear generators have similar flexibility parameterization in this study. Due to ongoing uncertainty with projecting coal and nuclear generation capacity, coal and nuclear generation is reported together in tables and graphs. For the Base scenario assumptions, we assume this category is slightly more flexible than the aggregate mix of coal and nuclear units today. For the Must Run-70\% scenario, we assume flexibility that is comparable to the aggregate mix of coal and nuclear units today (including requiring must-run status at $25 \%$ of the capacity of the entire category).

${ }^{c}$ This is an extra cost in the modeling to send power from one region to another.

\section{Findings}

The analysis simulated operation of the Eastern Interconnection in detail, with a focus on examining indicators of system stress, including utilization of peaking generation, generator headroom, penetration of synchronous generation, and curtailment. System stress, as it is defined here, is not necessarily indicative of reliability or long-term economic concerns. However, it does indicate a system that operates differently from the power system has operated in recent decades. For example, VG curtailment can provide many services to the grid (e.g., flexibility and operating reserves), but it does indicate frequent and persistent near-zero marginal prices or other potential financial or physical conditions. Similarly, the operational stress metrics do not indicate a reliability problem, but they may indicate operation with reliability services (e.g., frequency and voltage support) coming from different sources compared to today. Understanding all the implications of these circumstances would require additional study. 
The following are key findings from the scenario simulations. Unless otherwise noted, all results presented are for the U.S. portion of the Eastern Interconnection.

\section{Finding 1: Balancing $70 \%-75 \%$ renewables $(68 \%-73 \%$ wind and solar) at five-minute levels in the Eastern Interconnection is possible while maintaining $99.99 \%$ of required reserves across the scenarios.}

Reserves are held in the model based on short-term uncertainty in renewable generation using the methodology used in ERGIS, which requires more reserves to be held for renewables. Balancing at such a high VG penetration leads to curtailment of $7 \%-10 \%$ in the two base scenarios. Decreasing operational flexibility increases the need to curtail VG (9\%-14\% total VG curtailment) to balance the system. The decreased flexibility also increases the cost of operations by $\$ 2$ billion- $\$ 3$ billion per year, and it increases total emissions from power generation. This finding assumes frequency support will be provided without requiring additional thermal generation to be online. These solutions could include synthetic inertia, synchronous condensers, and other technologies.

The types of generation each scenario uses to balance the system are shown in Figure ES-1. In the Must Run-70\% scenario, coal and nuclear resources generate more, while gas, wind, and solar resources generate less (leading to more curtailment). In the VG Limit-70\% scenario, both combined cycle natural gas and coal units generate more, leading to more curtailment. Generation differences are much smaller in the Hurdle Rate-70\% scenario, where additional natural gas combined cycle generation leads to more curtailment.

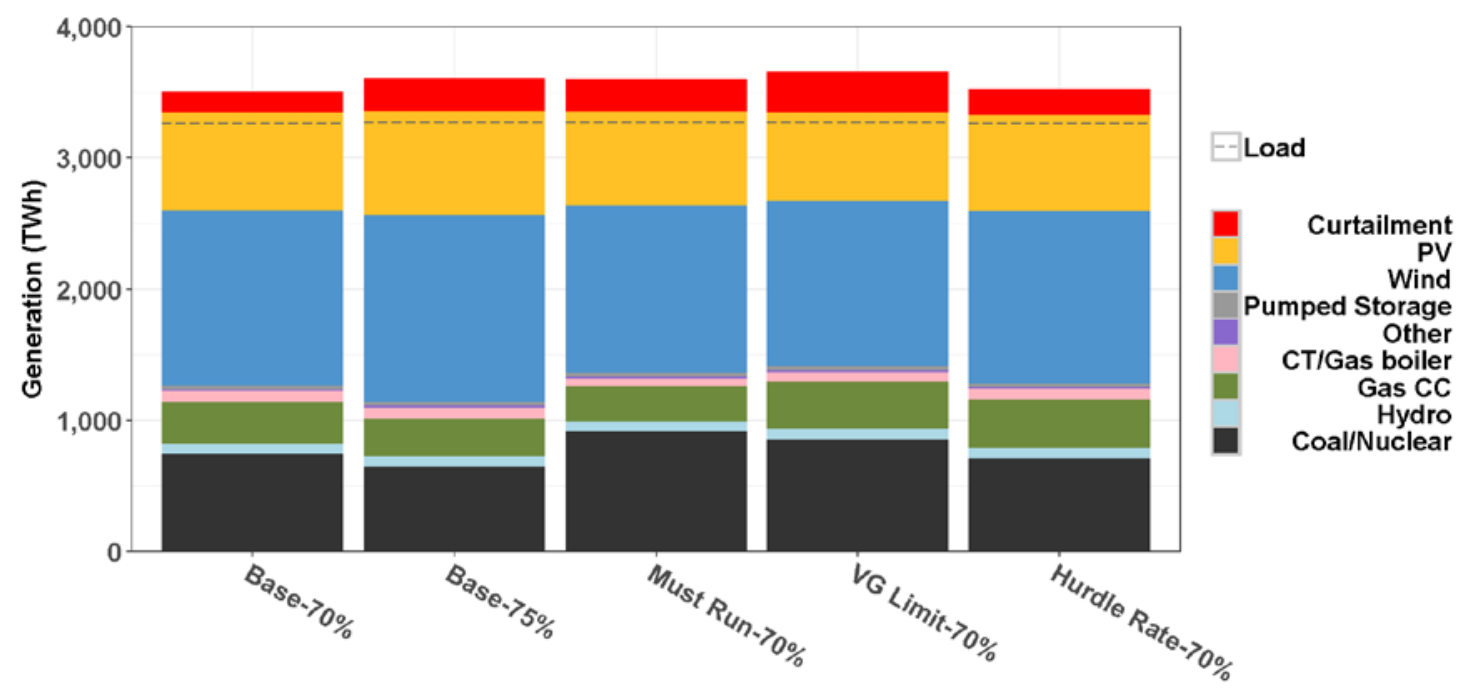

Figure ES-1. Total annual U.S. Eastern Interconnection generation

Table ES-2 shows the total production costs required to balance the system in each scenario. Production costs are the costs to operate the system; they do not include the capital costs associated with the deployment of generation and transmission capacity. The Base-75\% scenario has a higher renewable penetration, and lower production costs due to lower fuel costs. The flexibility challenges in the less flexible scenarios lead to annual production cost increases of \$2 billion-\$3 billion, which are primarily driven by higher curtailment, which requires additional operation at fossil-fueled units. 
Table ES-2. Total Annual Production Costs by Scenario (billion dollars)

\begin{tabular}{lcc}
\hline Type & $\begin{array}{l}\text { Total Annual } \\
\text { Production Cost }\end{array}$ & $\begin{array}{l}\text { Difference from } \\
\text { Base-70\% }\end{array}$ \\
\hline Base-70\% & 48.0 & $\mathrm{n} / \mathrm{a}$ \\
\hline Base-75\% & 45.0 & -3.0 \\
\hline Must Run-70\% & 50.0 & +2.0 \\
\hline VG Limit-70\% & 51.2 & +3.2 \\
\hline Hurdle Rate-70\% & 50.0 & +2.0 \\
\hline
\end{tabular}

Across the scenarios, VG curtailment is zero or near zero, for more than half the year. There are tens to hundreds of gigawatts (GW) of unused potential wind or solar generation (see Figure ES2) for approximately one-fourth of the year. The Base- $70 \%$ scenario sees the smallest number of hours with large amounts of curtailment, as more than 50 gigawatts (GW) are curtailed during roughly $10 \%$ of the year. The VG Limit- $70 \%$ scenario curtails more than $50 \mathrm{GW}$ approximately twice as often as the Base-70\% scenario, and it outpaces all other scenarios with the frequency and magnitude of curtailment. Storage, demand response, and other technical solutions to curtailment might be very useful in these scenarios. These would add flexibility to the system and primarily be solutions to shift energy in time or space; they were not modeled (beyond existing infrastructure) in these scenarios.

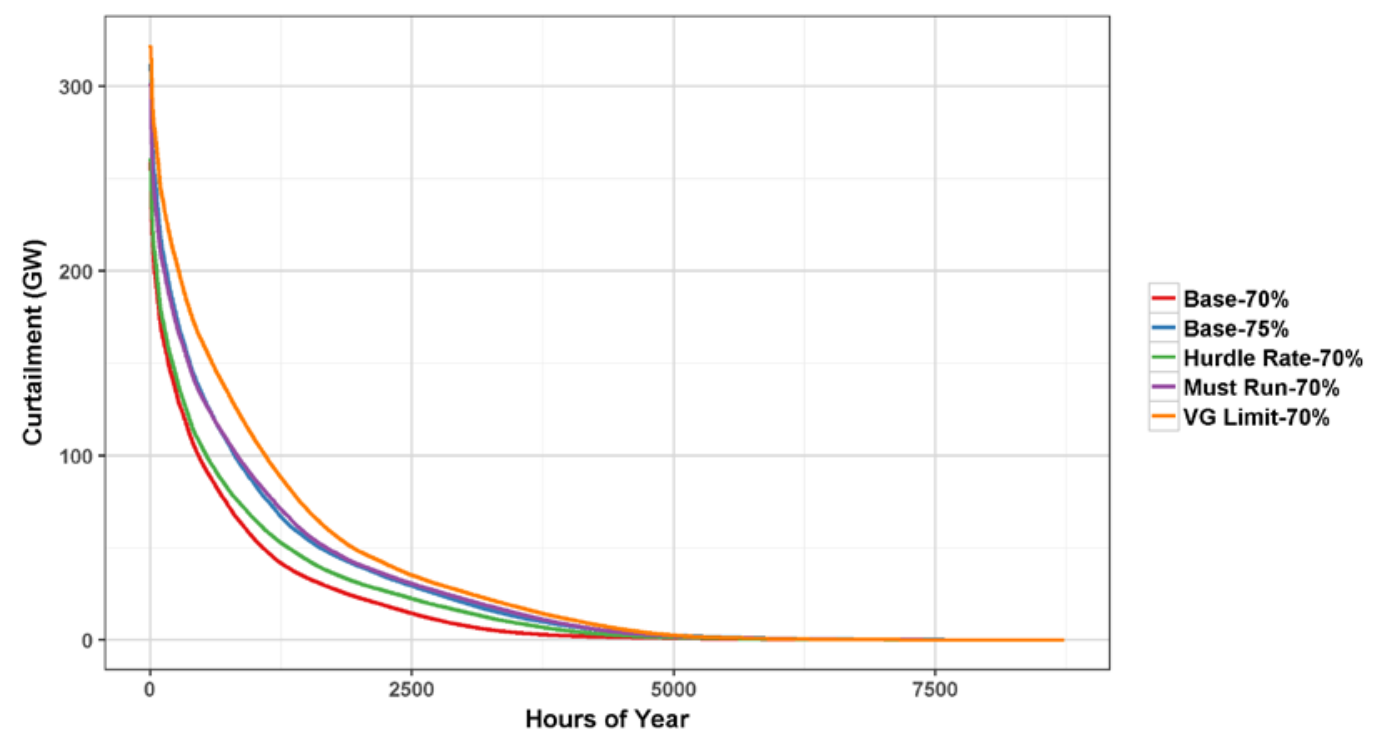

Figure ES-2. VG curtailment annual duration curve

Finding 2: The decreased flexibility explored in the VG Limit-70\%, Must Run-70\%, and Hurdle Rate-70\% scenarios reduces the number of hours with very high instantaneous 


\section{penetrations of VG, but the scenarios do not lead to the system holding additional spare online thermal capacity. ${ }^{1}$}

The penetration of non-synchronous generation on the system is one possible sign of operational stress. This metric refers less to balancing stress and more to concerns about low levels of inertia on the system. More work is needed to determine which levels of non-synchronous penetration may be concerning based on region size, topology, and other parameters. In today’s grid, frequency support to maintain reliable operation is primarily provided by inertia from synchronous units, such as coal, gas, nuclear, and hydropower units. In a grid with high penetration of wind and solar, frequency support would need to be provided by additional sources (which could include controls at inverter-based generators, synchronous condensers, or other technologies).

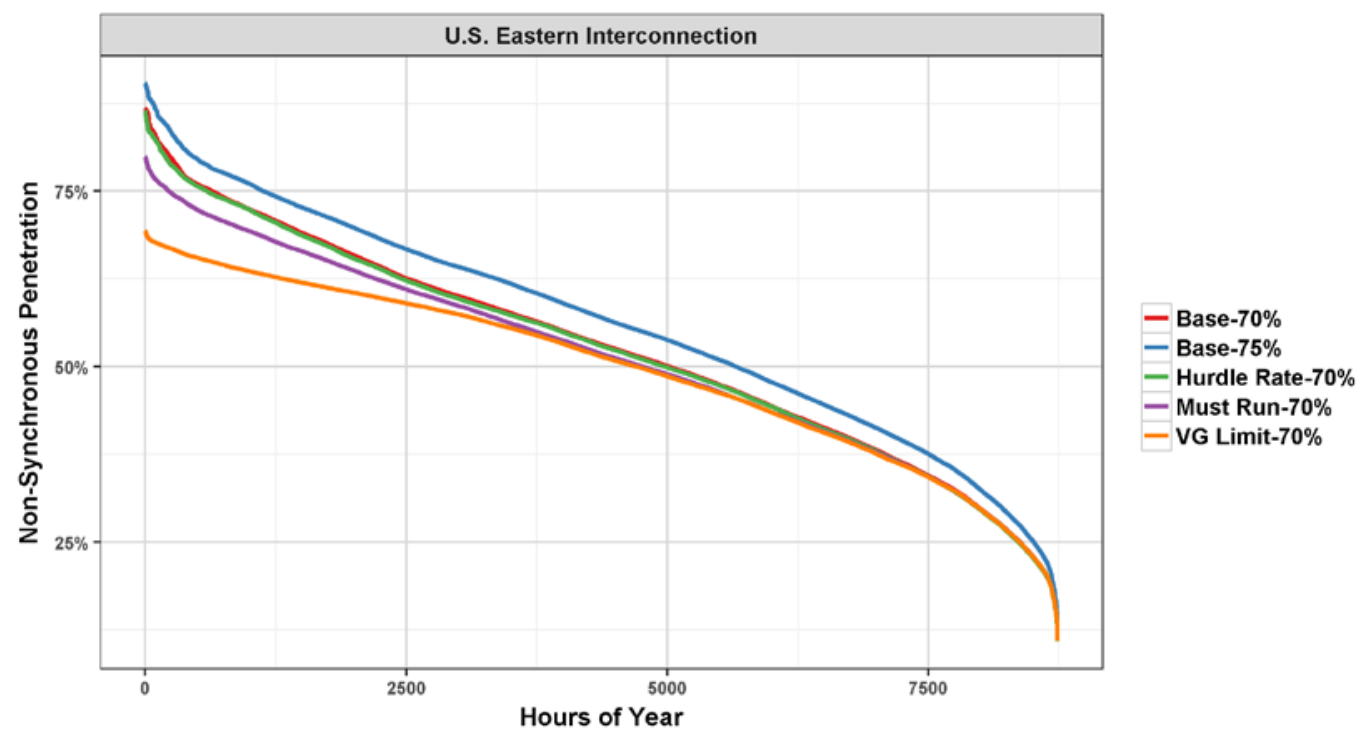

Figure ES-3. Duration curves of non-synchronous generation on the system

The flexibility sensitivities substantially impact the non-synchronous penetration ${ }^{2}$ (see Figure ES-3). In the U.S. Eastern Interconnection, all scenarios stay below 75\% non-synchronous penetration for all but 1,000 hours of the year, but within those 1,000 hours, the penetration changes significantly depending on the system flexibility assumptions. The VG Limit-70\% scenario maintains the lowest non-synchronous penetration given that it forces $25 \%$ of all generation to come from non-inverter-based generators. The Must Run-70\% scenario also limits the highest non-synchronous penetrations seen in the other three scenarios, but it has similar nonsynchronous penetrations to the Base-70\% scenario for much of the year. In all cases, the less flexible scenarios curtail VG to limit the non-synchronous penetration.

\footnotetext{
${ }^{1}$ The system's ability to use the spare online capacity available is limited by each generator's ramp rate, but that is not considered in these particular metrics. Ramp rates are considered in the modeling; continued system evolution could lead to future generation portfolios with more flexible characteristics (e.g., higher ramp rates and lower minimum generation levels).

2 The non-synchronous penetration is calculated as the generation from wind and solar divided by the sum of the online capacity of non-inverter-based generators (thermal and hydro) and the generation from wind and solar.
} 


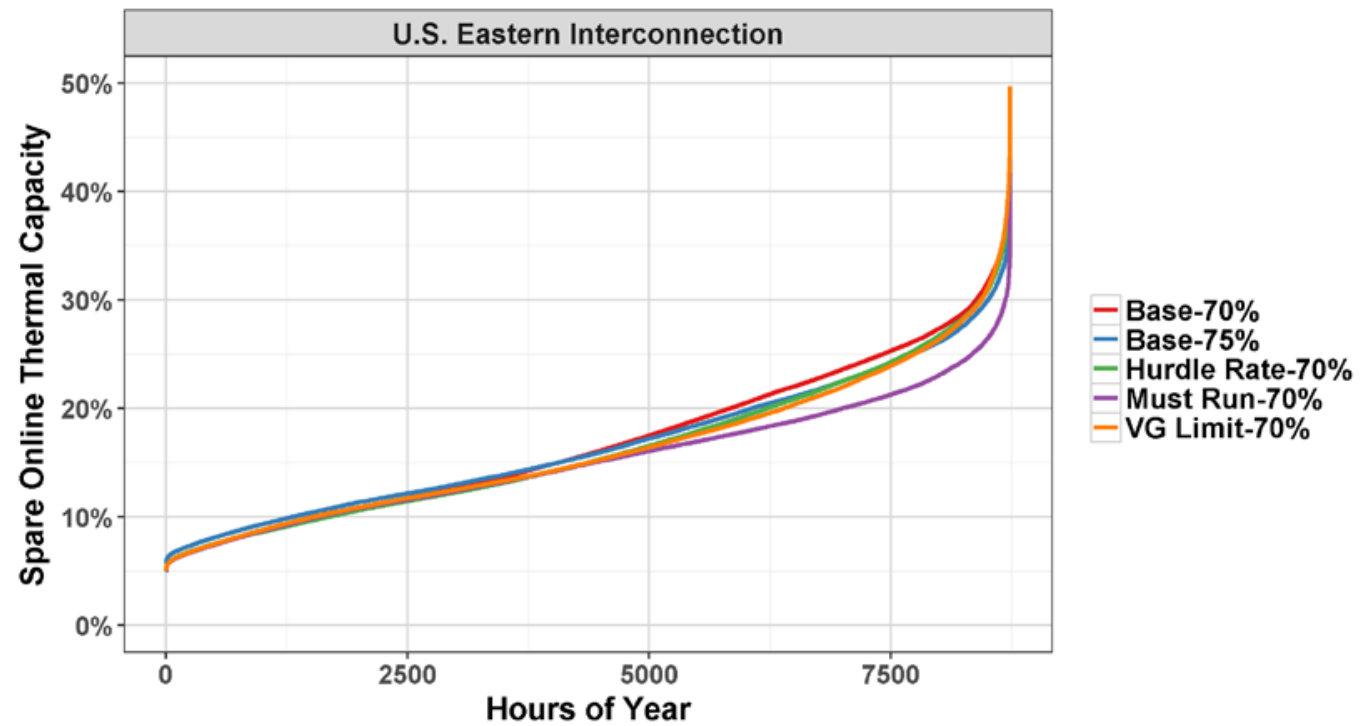

Figure ES-4. Spare online capacity for thermal units by region, including capacity used for reserves

However, the inflexibility that limited the non-synchronous penetration did not lead to additional spare online thermal capacity, which is another potential sign of system stress (see Figure ES-4). A low percentage of spare online thermal capacity means the thermal fleet is operating near its maximum capacity and may need to turn on quick-start generators, such as combustion turbines, to deal with large and unexpected increases in the load (or reductions in VG generation). In contrast, a high percentage of spare online thermal capacity means the system can use its online generation to deal with increases to the net load and is in a more stable state to deal with such a disturbance.

Finding 3: The day-ahead market simulation predicts, with reasonable accuracy, the curtailment and generation from wind and solar resources. However, it does not accurately predict the need for peaking/quick-start generation from natural gas combustion turbines.

High curtailment of renewable energy and the associated low marginal costs indicate possible economic stress to the owners of generators, but do not necessarily strain system operations or impact reliability. The day-ahead market simulation schedules curtailment in hourly time blocks, although that curtailment is not fixed. At the penetration levels explored in this study, a large portion of the curtailment is scheduled by the day-ahead unit commitment.

Figure ES-5 shows the correlation between the scheduled curtailment and the actual hourly curtailment. The red line in each plot is a 1:1 line. If the scheduled curtailment perfectly predicted actual curtailment, all points would fall on the line. The actual curtailment tends to be slightly larger than the scheduled curtailment, as can be seen by the higher density of points above the red line. This is mostly due to the five-minute variability that can lead to additional curtailment over what was scheduled. Nevertheless, the scheduled curtailment generally accurately estimates actual curtailment. 
The day-ahead also schedules gas combustion turbine (Gas CT) usage, but similar to curtailment, it is not actually fixed in the real time. Scheduled Gas CT usage does not necessarily indicate stress for the system, but deviating from the day-ahead Gas CT schedule could. Figure ES-6 shows the correlation between generation from CTs in the real-time economic dispatch and the scheduled CT generation in the day-ahead unit commitment in the Base-70\% scenario. In general, there is little correlation between the scheduled and actual generation across all scenarios. More study, potentially looking at the benefits of intraday re-commitment using intraday forecasts, is needed on this issue.

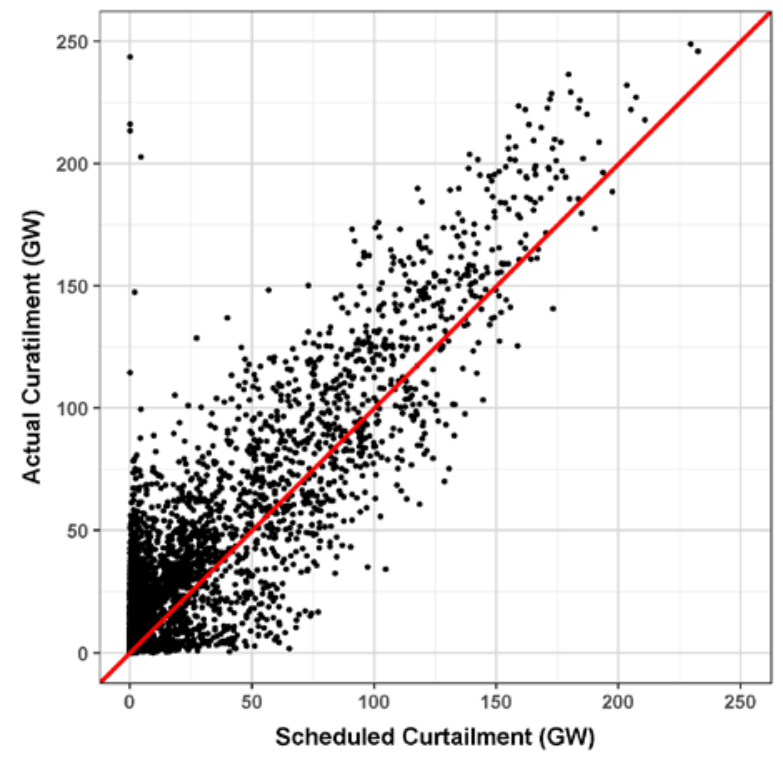

Figure ES-5. Actual curtailment compared to the amount of curtailment scheduled in the Day-Ahead Unit Commitment step for the Base- $70 \%$ scenario.

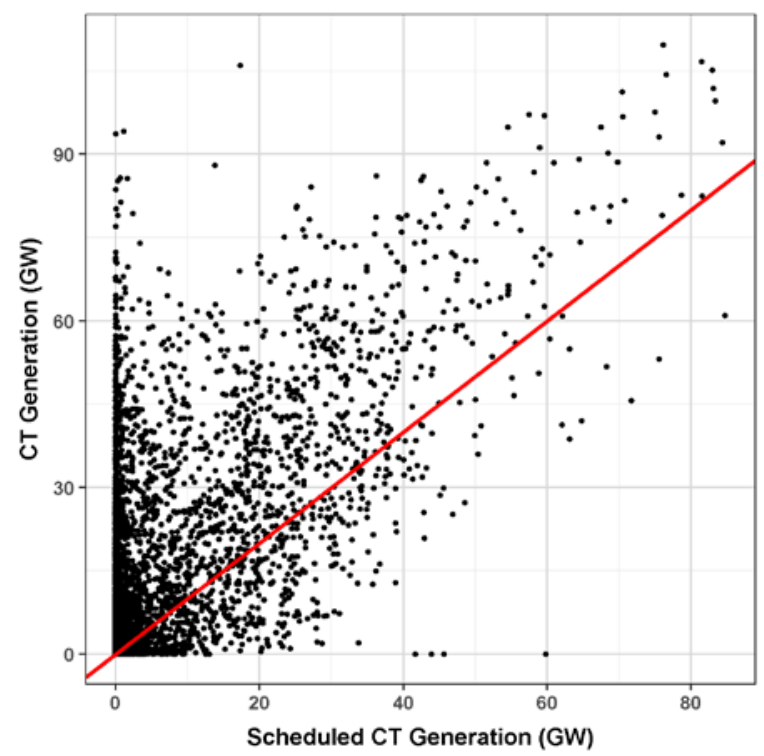

Figure ES-6. Real-time combustion turbine (CT) generation vs day-ahead scheduled CT generation for the Base-70\% scenario.

The red-line in each figure is a 1:1 line.

\section{Additional Caveats and Limitations}

The following limitations, in addition to those given in the introduction to the report (Section 1) and elsewhere in the Executive Summary, are associated with the analysis and the findings discussed above.

Simplified transmission modeling was conducted both to reduce compute time and because this was not a transmission-focused study. While reasonable limits were modeled, local transmission issues associated with such transformational change to the grid were not considered in the analysis. The interregional transmission buildout is identical for all the scenarios studied.

The simulations modeled a day-ahead and real-time market for the Eastern Interconnection. As in ERGIS, no intraday market was simulated. This approach made it more challenging to schedule the natural gas combined cycle fleet compared to a system that includes intraday markets, as these generators must be scheduled using day-ahead forecasts. Stoll et al. (2016) showed that four-hour-ahead unit commitment may have relatively modest impacts on a very 
large power system, because uncertainties such as forecast errors are reduced with the diversity a large power system provides.

More work is needed to determine what levels of non-synchronous penetration are concerning based on region size, topology, and other parameters.

Finally, while this study analyzes curtailment, resource adequacy, transmission availability, and operational and economic stresses at these penetrations, an understanding of the dynamic stability of such high VG systems is also needed, including the implications for frequency response, voltage stability, and other dynamic issues, to confirm the reliability of operation of these scenarios. 


\section{Table of Contents}

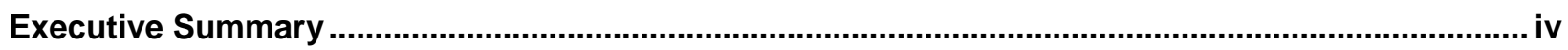

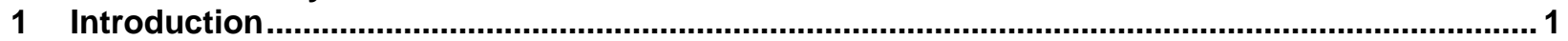

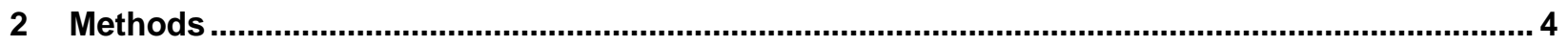

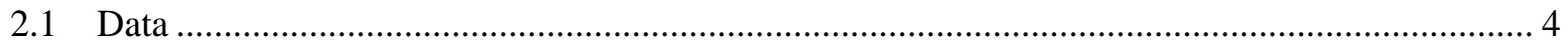

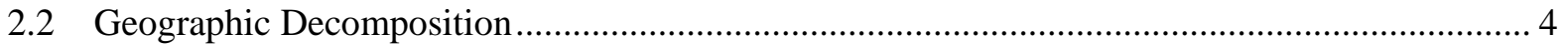

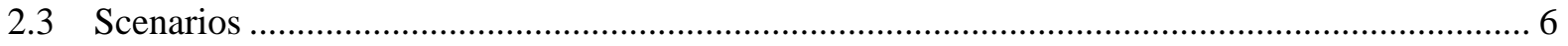

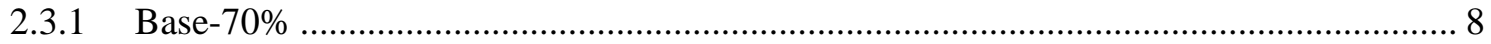

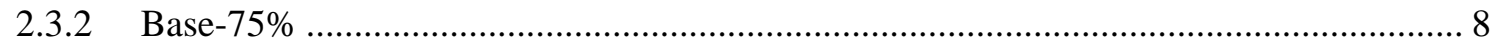

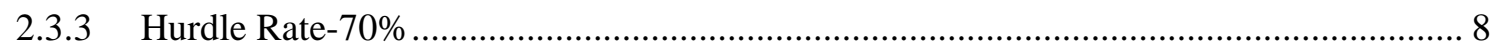

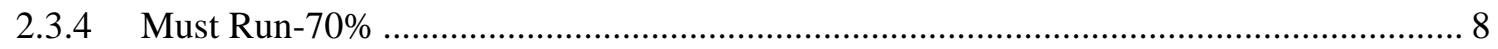

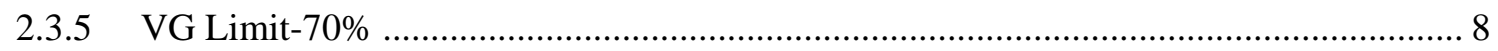

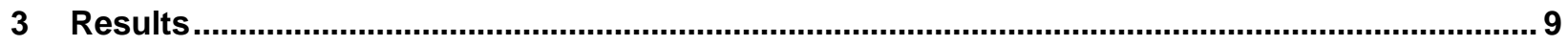

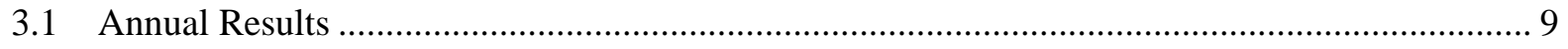

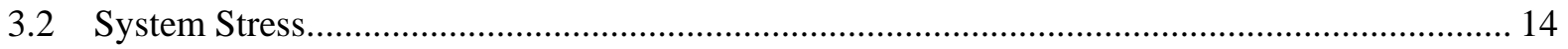

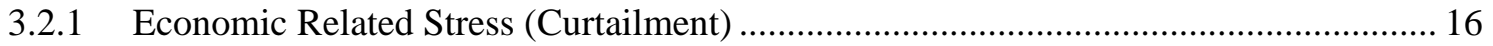

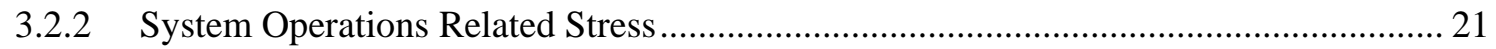

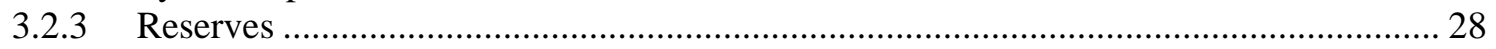

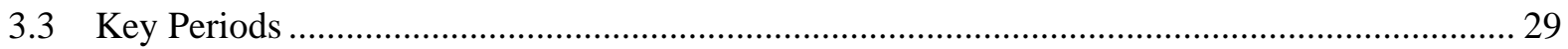

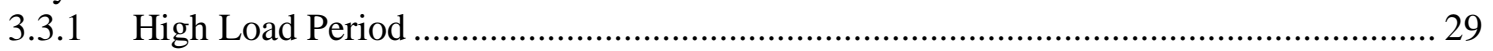

3.3.2 High Instantaneous VG Penetration ...................................................................... 32

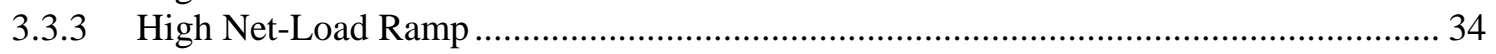

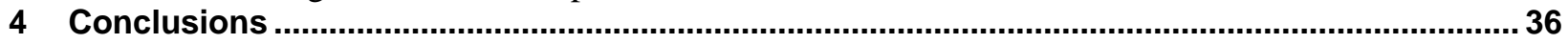

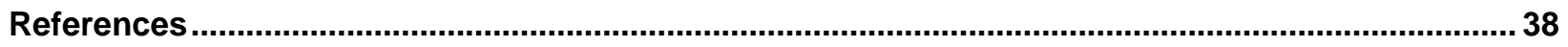




\section{List of Figures}

Figure ES-1. Total annual U.S. Eastern Interconnection generation ...................................................... vii

Figure ES-2. VG curtailment annual duration curve ......................................................................... viii

Figure ES-3. Duration curves of non-synchronous generation on the system by region ............................ ix

Figure ES-4. Spare online capacity for thermal units by region, including capacity used for reserves........ $\mathrm{X}$

Figure ES-5. Actual curtailment compared to the amount of curtailment scheduled in the Day-Ahead Unit

Commitment step for the Base-70\% scenario..................................................................... xi

Figure ES-6. Real-time combustion turbine (CT) generation vs day-ahead scheduled CT generation for the Base-70\% scenario.......................................................................................................

Figure 1. Map of 33 transmission zones used for the study (based on ERGIS zones) ............................... 1

Figure 2. Map of transmission expansion used for this study (based on EIPC Scenario 1)......................... 2

Figure 3. Stage 1 of geographic decomposition: Day-ahead interconnection-wide simplified optimization to determine flow schedules.................................................................................................. 5

Figure 4. Stage 2 of geographic decomposition: Day-ahead regional optimizations based on flow schedules from Stage 1 ................................................................................................ 5

Figure 5. Stage 3: Interconnection-wide optimization of real-time dispatch based on unit commitment

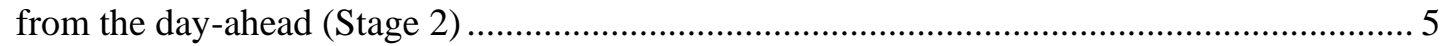

Figure 6. Total annual U.S. Eastern Interconnection generation ....................................................... 10

Figure 7. Difference in total annual U.S. Eastern Interconnection generation compared to the Base-70\%

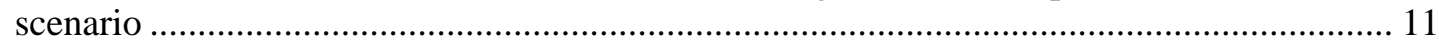

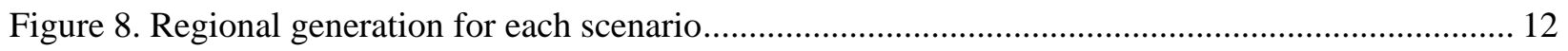

Figure 9. Reserves provided by generator type.................................................................................... 13

Figure 10. Price duration curve for each U.S. Eastern Interconnection region......................................... 15

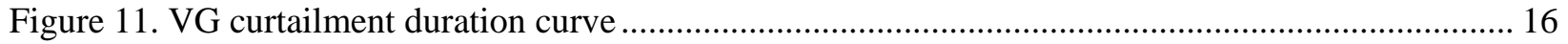

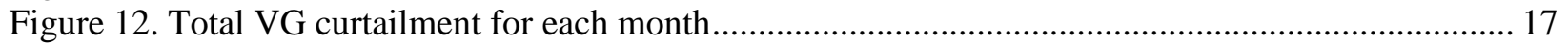

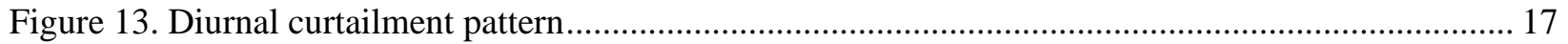

Figure 14. Curtailment compared to the amount of curtailment scheduled in the Day-Ahead

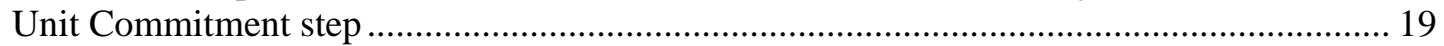

Figure 15. Hourly VG generation compared to hourly scheduled VG generation in the Base scenario .... 20

Figure 16. Five-minute VG generation compared to hourly scheduled VG generation ............................ 21

Figure 17. Duration curve of spare online thermal capacity, including capacity used for reserves............ 22

Figure 18. Duration curve of spare online capacity (thermal and VG curtailed capacity)......................... 24

Figure 19. Duration curve of non-synchronous generation on the system.............................................. 25

Figure 20. Annual capacity started for coal and nuclear, natural gas combined cycle units, and

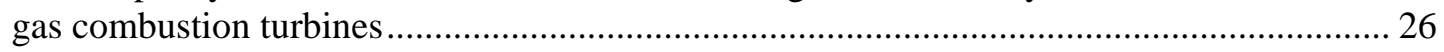

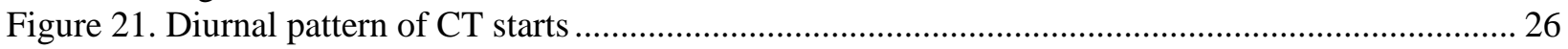

Figure 22. Real-time CT generation vs day-ahead scheduled CT generation.......................................... 28

Figure 23. U.S. Eastern Interconnection peak load period ............................................................... 30

Figure 24. Commitment and dispatch during U.S. Eastern Interconnection peak load period ................... 31

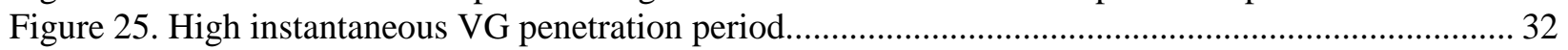

Figure 26. Commitment and dispatch during high instantaneous VG penetration period.......................... 33

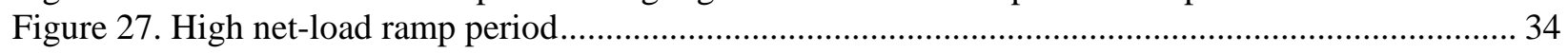

Figure 28. Commitment and dispatch during high net-load period ....................................................... 35

\section{List of Tables}

Table 1. Thermal Generator Parameters .............................................................................................. 3

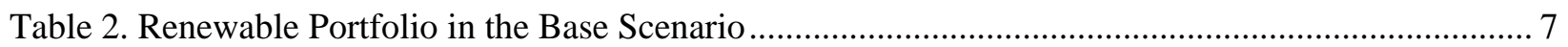

Table 3. Wind and Solar Capacity in the Base Scenario....................................................................... 7

Table 4. Summary of Modeled Renewable Penetration (\% of annual energy) in all Scenarios ................... 9 
Table 5. Total Production Costs by Scenario (million dollars).

Table 6. Curtailment Scheduled in Day-Ahead .

Table 7. Reserve Deployment by Scenario..... 


\section{Introduction}

In the Renewable Electricity Futures Study (RE Futures), Mai et al. (2012) analyzed some of the costs and technical impacts to the power grid of integrating large amounts of renewable electricity generation (up to $90 \%$ annual penetration) into the U.S. power system. RE Futures analyzed renewable resource potential, direct costs associated with developing those resources, and potential technical challenges of integrating generation from these resources into the grid. The analysis also included hourly production cost modeling of several different scenarios to identify some of the operational impacts of high penetrations of variable renewable generation (41\%-47\% penetration of variable generation by 2050). The report concluded that additional research was needed to understand whether the system could be operated at subhourly time scales and during transient events.

To address operational impacts at subhourly time scales, analysis has been conducted on the two large U.S. interconnections. Brinkman (2015) performed subhourly analysis using newer methodologies and updated data sets for transmission and generation infrastructure in the Western Interconnection to analyze the integration of very high annual penetrations (82\%-88\%) of renewable generation, including 38\%-45\% penetration of variable generation (VG) resources. VG resources include wind and solar photovoltaics (PV), which have generation patterns that are variable. The analysis described in this report focuses on the Eastern Interconnection.

Operational costs are analyzed in the present analysis, but previous and ongoing work have also studied the overall costs (capital and operational costs) of scenarios with high penetrations of renewable generation. In the National Renewable Energy Laboratory (NREL) Standard Scenarios report, Cole et al. (2017) analyze the cost and evolution of high penetration scenarios in detail and include a Mid-case scenario that assumes business as usual for the electric grid. The Mid-case scenario models a $45 \%$ penetration of renewable resources in the United States. ${ }^{3}$ The $80 \%$ National RPS scenario assumes an $80 \%$ penetration of renewable resources; costs for this scenario are approximately $8 \%$ higher than the Mid-case, while carbon emissions are $76 \%$ lower (the Mid-Case represents a 20\% reduction from today's emissions in 2050, in spite of significant load growth). The Standard Scenarios work and the present analysis both consider standard geographic exclusions when siting the renewable generation, but they do not consider potential challenges associated with such large-scale increases to land use for wind and solar development or transmission.

The scenarios created for this analysis were informed by the Eastern Renewable Generation Integration Study (ERGIS [Bloom et al. 2016]) and the NREL Standard Scenarios analysis (Cole et al. 2016), specifically the $80 \%$ National RPS scenario from the latter. Consequently, the scenarios are not meant to be projections or endorsements of future deployments of generation technologies, but rather, they represent a possible geographic distribution of renewable generation technology deployments should they collectively reach very high penetration levels.

There are two key differences between the scenarios explored in this work and the ones for the Western Interconnection in Brinkman (2015). The Eastern Interconnection does not have as much available resources for hydropower, geothermal power, or concentrating solar power.

\footnotetext{
${ }^{3}$ For reference, the Energy Information Administration’s Annual Energy Outlook 2018 (AEO 2018) Reference Case projects 31\% renewable penetration in 2050 .
} 
In addition, the capital costs of VG have decreased significantly in the last several years. Thus, the scenarios studied here have VG penetrations ranging from $64 \%$ to $73 \%$ (after curtailment).

The subhourly analysis in this study and that in Brinkman (2015) assessed whether it is possible to balance supply and demand at five-minute intervals throughout the year with these high levels of VG penetration. Neither study performed a detailed reliability analysis, which would include dynamic stability analysis.

Other studies have analyzed scenarios with VG penetrations close to and above $50 \%$ regionally. In North America, these studies tend to be on states or regions with renewable portfolio standards that require significant quantities of renewable penetration on the grid. Examples of studies that use stakeholder-reviewed methodologies and assumptions include the California Low Carbon Grid Study (Brinkman et al. 2016), California ISO (Liu 2014), and subsequent Union of Concerned Scientists work (Nelson and Wisland 2015), a Western Interconnection flexibility assessment by Schlag et al. (2015), and an analysis of high solar penetrations in California by Denholm et al. (2015). In addition, DNV GL (2014) studied up to 68\% penetration of renewables in Europe, with VG making up a little less than half of the overall annual electricity generation.

While previous published studies have analyzed renewable penetrations close to $100 \%$ (some of which included very high penetrations of VG), most do not use the detailed methodology, assumptions, and stakeholder review used by the above-mentioned studies (Heard et al. 2017).

Following up on the $80 \%$ renewable penetration scenarios analyzed hourly in the original RE Futures study, MacDonald et al. (2015) used hourly modeling to analyze carbon mitigation scenarios of up to $80 \%$ carbon reduction. Very few studies have performed subhourly modeling on VG penetrations above $70 \%$ for large regions.

The general conclusions of most of these studies are that the renewables can be integrated from a technical standpoint most smoothly if operational practices become more flexible and the flexibility of the grid continues to adapt and evolve (e.g., through increased cooperation between balancing authorities and with renewable generators providing ancillary services back to the grid). This study analyzes higher VG penetrations than these studies and includes subhourly operational modeling.

The key goals of this analysis are to perform detailed operational modeling of scenarios with very high (above 70\%) annual penetrations of variable generation in the U.S. Eastern Interconnection to:

1. Assess the ability to balance supply and demand for electricity at five-minute time intervals

2. Assess the impact of potential grid operating practices that could reduce flexibility (and identify possible mitigating measures) on power system balancing

3. Report on a set of metrics that reveal periods of potential stress on the system. 
In addition to assessing the ability to balance supply and demand at five-minute time resolution with very high VG penetrations in the Eastern Interconnection, this study focuses on understanding the implications of different amounts of physical and institutional flexibility on balancing. In addition to the base case (71\% renewables), we also modeled a scenario with higher VG penetrations (73\%), for a total renewable penetration (including hydropower) of 75\%.

We also model a scenario with more must-run thermal generators, a scenario with less efficient transmission scheduling practices, and a scenario that requires $25 \%$ of load to be served by local, non-inverter-based generation at all times. An analysis of system "stress" is also presented in this report. Our analysis estimates the amount of spare online capacity available in the system, nonsynchronous penetration levels, day-ahead compared to real-time curtailment, starts of peaking generation, and other metrics. Storage and demand-side participation are important aspects of a high-penetration future, but this study focuses on what can be done without extensive storage or demand-side participation. These technologies could be particularly important to go beyond $70 \%$ VG penetration.

The methodology and data sets used in this study are primarily based on the Eastern Renewable Generation Integration Study (Bloom et al. 2016). A new method for geographic decomposition of the power system was employed in this study to more accurately describe the way the interconnection is operated, to reduce computational size, and to allow for more complexity within the optimization. The methods and data sets are described Section 2, while the results are in Section 3. Conclusions are summarized in Section 4.

Some relevant aspects of a high renewable penetration future are not addressed directly in the present analysis. It is not a comprehensive analysis of all the operational reliability aspects, (including what the North American Electric Reliability Corporation identifies as "essential reliability services") needed to ensure reliable production and delivery of electricity to the consumer. Our analysis looks at relevant metrics, but it is not a rigorous analysis of voltage or frequency stability, black start, or other reliability needs. These aspects of high penetration scenarios will need to be studied in future work and to build on previous studies such as Miller et al. (2014). 


\section{Methods}

This study expands on the work done for ERGIS (Bloom et al. 2016) by building on the data sets and methods used for that study and adding new scenarios, including cases that address much higher renewable penetrations. The modeled five-minute operation of the grid is done using the PLEXOS production cost model, Version 6.4, Release 2. The NREL Peregrine High Performance Computing system was used for initial runs on a variety of scenarios for this study; the final runs reported here were done on standard (dual-processor) hardware.

\subsection{Data}

The base PLEXOS production cost modeling data set used for this study is the model used for ERGIS. This data set was built from various sources, including Energy Exemplar (the vendor of PLEXOS), the Eastern Interconnection Planning Collaborative (EIPC), the U.S. Environmental Protection Agency Continuous Emissions Monitoring data, North American Electric Reliability Corporation (NERC) Generator Availability Data System, the Eastern Wind Integration and Transmission Study (for wind data), the Solar Integration National Dataset Toolkit, and other sources.

The key differences between this study and ERGIS are:

- The scenarios studied are very different; the portfolio of both thermal and renewable generation is different, as is described in Section 2.3.

- The transmission modeling is done zonally for this study (using the 33 transmission zones from ERGIS). The zones are represented in the model as single nodes connected by multiple lines, while in ERGIS a DC power flow was done using more than 60,000 nodes.

- The optimization is done using geographic decomposition of the balancing authorities (see Section 2.2).

The simplified transmission modeling was done to save compute time and because this is not a transmission-focused study. Although reasonable limits are modeled, local transmission issues will certainly need to be addressed in this future scenario that models transformational change on the grid. Different shades are the transmission zones, while different colors are the larger regions that are used for geographic decomposition (see Section 2.2).

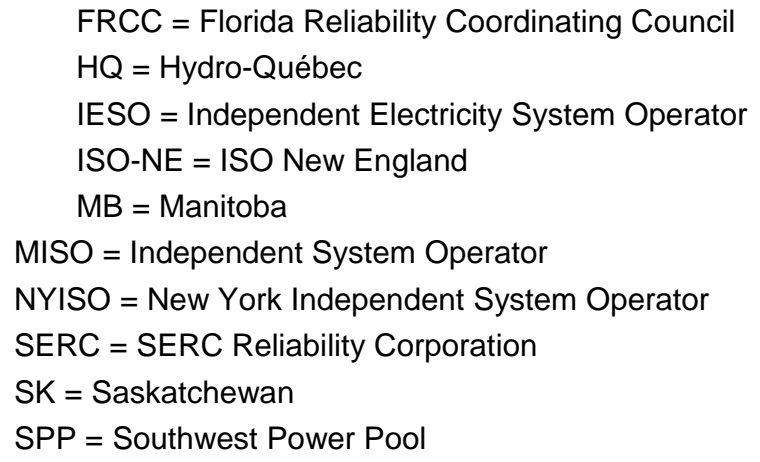


Figure 1 shows the transmission zones that were modeled for this study.

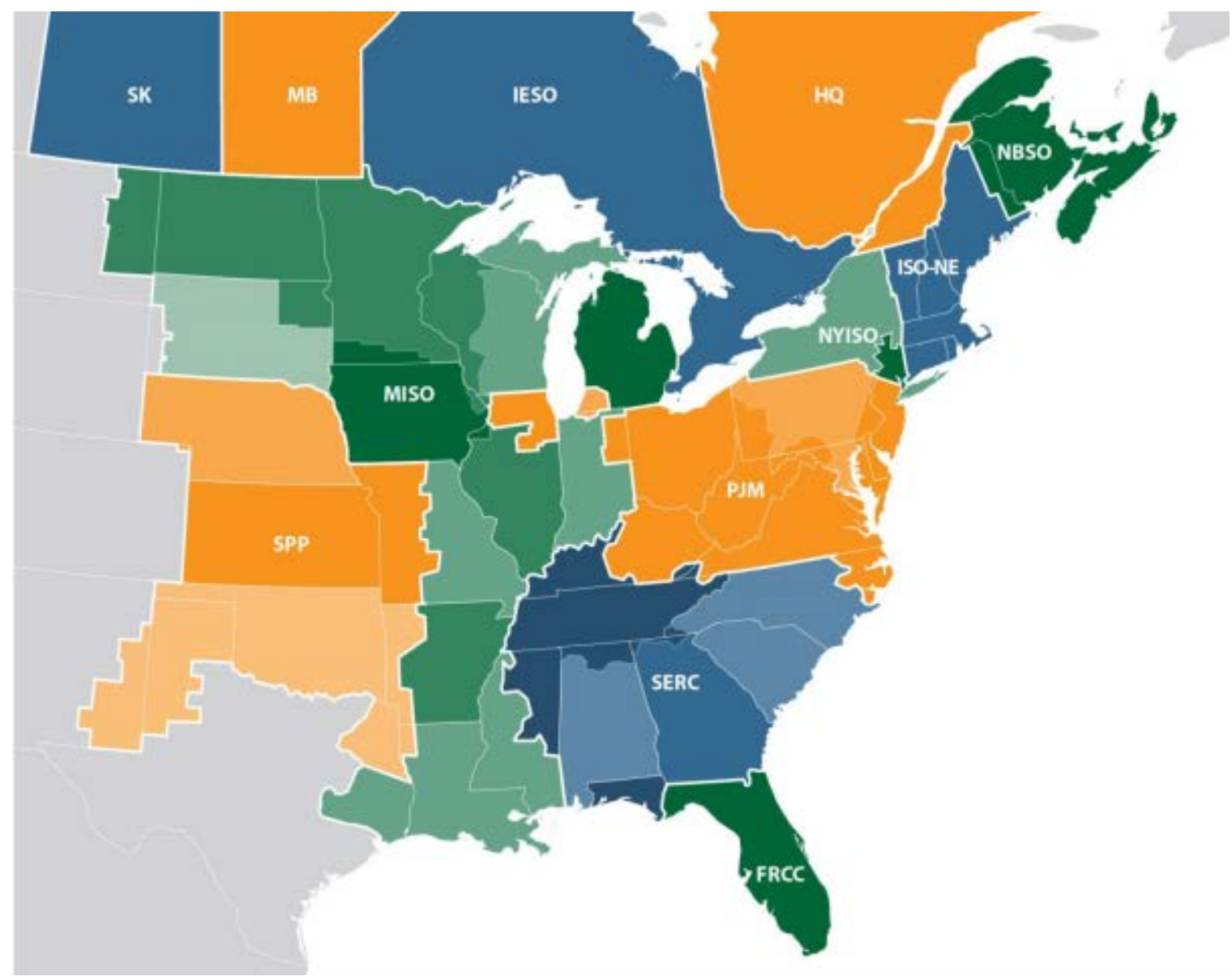

Different shades are the transmission zones, while different colors are the larger regions that are used for geographic decomposition (see Section 2.2).

FRCC = Florida Reliability Coordinating Council $\mathrm{HQ}=$ Hydro-Québec

IESO = Independent Electricity System Operator ISO-NE = ISO New England

$\mathrm{MB}=$ Manitoba

$$
\begin{aligned}
& \text { MISO = Independent System Operator } \\
& \text { NYISO = New York Independent System Operator } \\
& \text { SERC = SERC Reliability Corporation } \\
& \text { SK = Saskatchewan } \\
& \text { SPP = Southwest Power Pool }
\end{aligned}
$$

\section{Figure 1. Map of 33 transmission zones used for the study (based on ERGIS zones)}

The transmission lines and interfaces between regions include existing lines, planned lines, and an additional buildout. The additional buildout is the ITx30 buildout used for ERGIS (see Figure 2); it was originally sourced from the EIPC Scenario 1 transmission build. This scenario was developed to represent a future with major additions of energy efficiency, demand response, and renewable generation, along with the transmission expansion to support the additional renewable generation. ${ }^{4}$ The transmission buildout is assumed to be the same for all scenarios,

\footnotetext{
${ }^{4}$ For the purposes of this study, we assume no siting, institutional, economic or other difficulties that may arise with implementing this scenario in practice.
} 
and the capital costs of the buildout (and associated renewables) are not reported in this analysis. For total cost impacts of scenarios similar to this, see Cole et al. (2017).

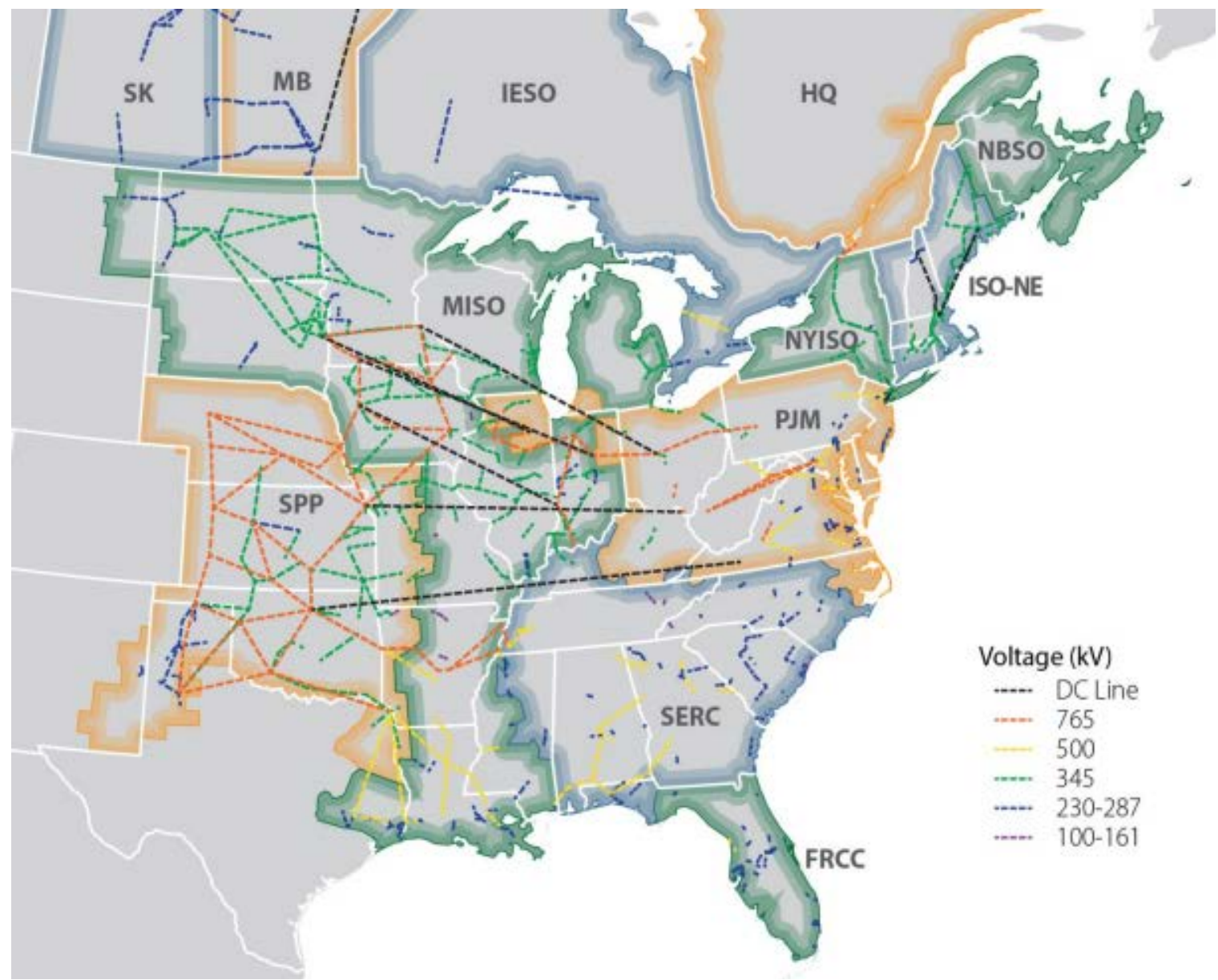

Figure 2. Map of transmission expansion used for this study (based on EIPC Scenario 1)

The natural gas fleet represented in this study used the same parameters as ERGIS. These are shown in Table 1. Due to ongoing uncertainty with projecting coal and nuclear generation capacity, we placed all coal generators and nuclear generators in a single category (referred to as Coal/Nuclear in plots) and reduced the aggregate capacity at these coal and nuclear generators by 25\%. Most scenarios used ERGIS coal assumptions to represent the coal and nuclear combined fleet (e.g., generators are not must-run and can be turned down), but in the Must Run-70\% scenario, we assumed $25 \%$ of the entire coal and nuclear fleet is must-run generation and cannot turn down). In the results of the modeling, we do not report any distinction between the coal and nuclear resources because we used the scenarios to understand the impact of flexibility (or inflexibility) at these resources. 
Table 1. Thermal Generator Parameters

\begin{tabular}{lcccc}
\hline & $\begin{array}{c}\text { Gas } \\
\text { Combustion } \\
\text { Turbine }\end{array}$ & $\begin{array}{c}\text { Gas } \\
\text { Combined } \\
\text { Cycle }\end{array}$ & Coal/Nuclear & $\begin{array}{c}\text { Must Run } \\
\text { (MW) }\end{array}$ \\
\hline $\begin{array}{l}\text { Min gen (\% of max } \\
\text { capacity) }\end{array}$ & 60 & 50 & $50\left(<600 \mathrm{MW}^{\mathrm{b}}\right)$ & $100 \%$ \\
$\begin{array}{l}\text { Heat rate at min gen (as a } \\
\text { \% of HR at max capacity) }\end{array}$ & 100 & 113 & 106 & $\mathrm{NA}$ \\
\hline $\begin{array}{l}\text { Ramp rate (\% of max cap } \\
\text { per minute) }\end{array}$ & 8 & 5 & 2 & $\mathrm{NA}$ \\
\hline $\begin{array}{l}\text { Start costs (\$/MW } \\
\text { capacity) }\end{array}$ & 69 & 79 & 129 & $\mathrm{NA}$ \\
\hline $\begin{array}{l}\text { Annual outage rate (sum of } \\
\text { planned and unplanned) }\end{array}$ & $7.6 \%-12.0 \%$ & $10.9 \%$ & $12.1 \%-17.1 \%$ & $8.9 \%-14.1 \%$ \\
\hline \begin{tabular}{l} 
Must-run status \\
\hline
\end{tabular} & No & No & No & Must-run \\
\hline
\end{tabular}

${ }^{a}$ In the Must Run-70\% scenario, $25 \%$ of coal and nuclear capacity is assumed to be must-run. In the other scenarios, all coal and nuclear generators follow the Coal/Nuclear properties (in terms of minimum generation levels, ramp rates, heat rate at minimum generation, and start costs).

All load, wind, and solar hourly and five-minute shapes are based on 2006 meteorology; the original source data for the hourly wind and solar were the Eastern Wind Integration and Transmission Study (EWITS) data set and the National Solar Radiation Database (NSRDB). Updates for forecasts and subhourly shapes are from ERGIS. Fuel prices are from ERGIS and based on the 2014 Annual Energy Outlook (AEO) forecast for 2026. Gas and coal prices vary regionally, and gas prices also vary monthly. Gas and coal prices average \$5.92 and \$2.90 per MMBtu, respectively. The gas prices are comparable, but not identical, to the AEO 2018 projections for 2050 (\$5.42). Hydro assumptions are directly from ERGIS, and they are intended to represent a typical water year in the United States and Canada, with hydro constraints, including monthly estimates of capacity, minimum generation levels, and energy limits.

The simulations modeled a day-ahead and real-time market for the Eastern Interconnection. As in ERGIS, no intraday market was simulated. This makes it more challenging to schedule the natural gas combined cycle fleet compared to a system that includes intraday markets, as these generators must be scheduled using day-ahead forecasts. However, Stoll et al. (2016) showed that four-hour-ahead unit commitment may have relatively modest impacts on a very large power system, because uncertainties such as forecast errors are reduced with the diversity provided by a large power system.

The day-ahead market was simulated using a novel geographic decomposition method developed specifically for these types of analysis. This method is described in Section 2.2. 


\subsection{Geographic Decomposition}

This study used a novel geographic decomposition method to simulate the operation of a single interconnection with multiple system operators. The flows between regions are determined in a simplified, interconnection-wide day-ahead unit commitment optimization. Instead of this optimization being used for generator scheduling, it is only used for scheduling transmission between the regions of the model. These flows are optimized within the modeling framework, but they are not perfectly optimal due to the simplifications that are made during this modeling step. This can represent some of the inefficiencies that exist between system operators in the United States. For a detailed description of the method and comparison with real operations, see Barrows et al. (submitted). The stages of the model for this study are:

- Stage 1 is a simplified optimization of the entire interconnection that sets the transmission flow schedules between regions. It has hourly resolution and uses day-ahead forecasts. The key simplifications are linear unit commitment (non-integer) and reduced unit commitment windows. Each optimization is over 24 hours instead of over 48 hours, which is often used in operational systems to properly (without too many end effects) optimize generator starts and shutdowns in the afternoon hours. In this stage, these startup impacts do not matter very much because of the linear optimization.

- Stage 2 is a geographically decomposed day-ahead unit commitment for each region (not a single interconnection-wide optimization). Each region has its own optimization, which includes flows to and from other regions that are based on the Stage 1 optimization.

- Stage 3 is the real-time dispatch for the entire interconnection. The regions are stitched back together for this optimization to enable the ability to adjust transmission schedules from the day-ahead runs (Stages 1 and 2). Although the flows themselves are not based on the day-ahead transmission schedules - the schedules are allowed to adjust, as they are today in most of the Eastern Interconnection-the unit commitment patterns in all regions are based on the Stage 2 optimization.

This geographic decomposition method follows actual operations between balancing authorities in a more realistic way than the assumed single, central optimization that is typically used for production cost modeling. In reality, balancing authorities dispatch their own systems, exchanging power with neighbors but not through a fully coordinated approach. Independent system operators operate markets that allow transactions between regions, but the markets are optimized independently. Outside independent system operators, markets for exchange of power do exist but dispatch decisions are not usually coordinated. The geographic decomposition approach used here uses a simplified dispatch to estimate flows between regions (Stage 1) and then optimizes day-ahead unit commitment for each region independently. This is more representative of the independent decisions made by the operators. It also reduces computation time compared to a fully detailed central optimization of the day-ahead market.

The stages of optimization are shown in Figure 3, Figure 4, and Figure 5. Figure 2 shows the seven regions in the United States that were run independently in the Stage 2 day-ahead unit commitment. All provinces in Canada were run as a single independent region because the study was focused on impacts of high renewable penetrations in the United States. 


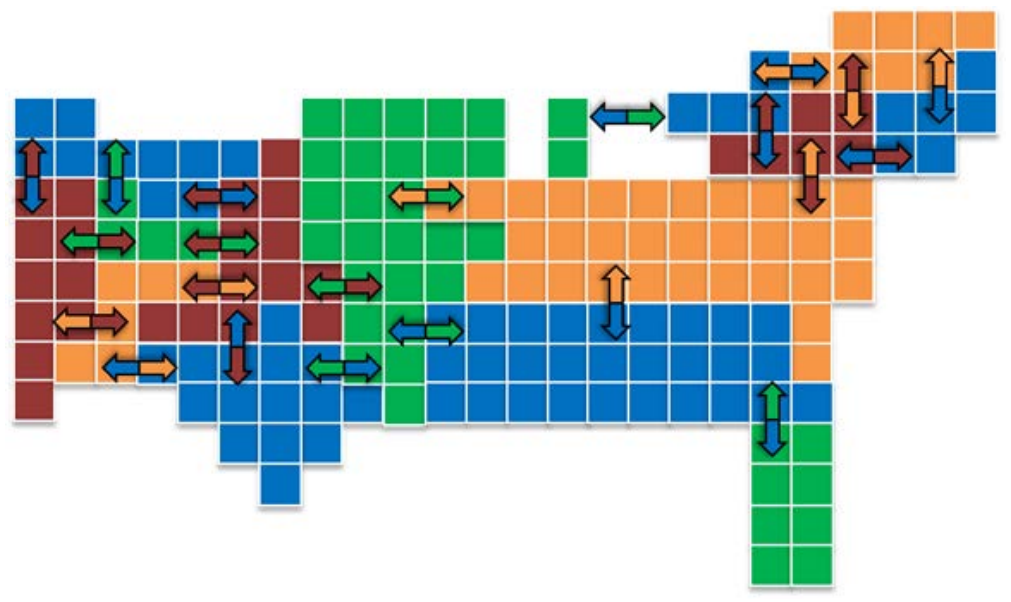

Figure 3. Stage 1 of geographic decomposition: Day-ahead interconnection-wide simplified optimization to determine flow schedules ${ }^{5}$

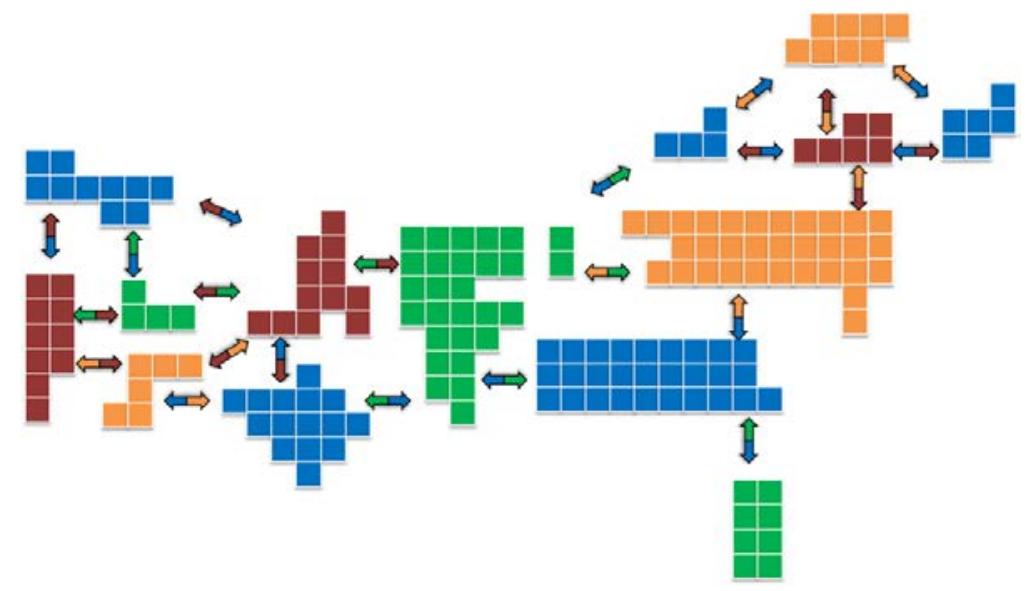

Figure 4. Stage 2 of geographic decomposition: Day-ahead regional optimizations based on flow schedules from Stage 1

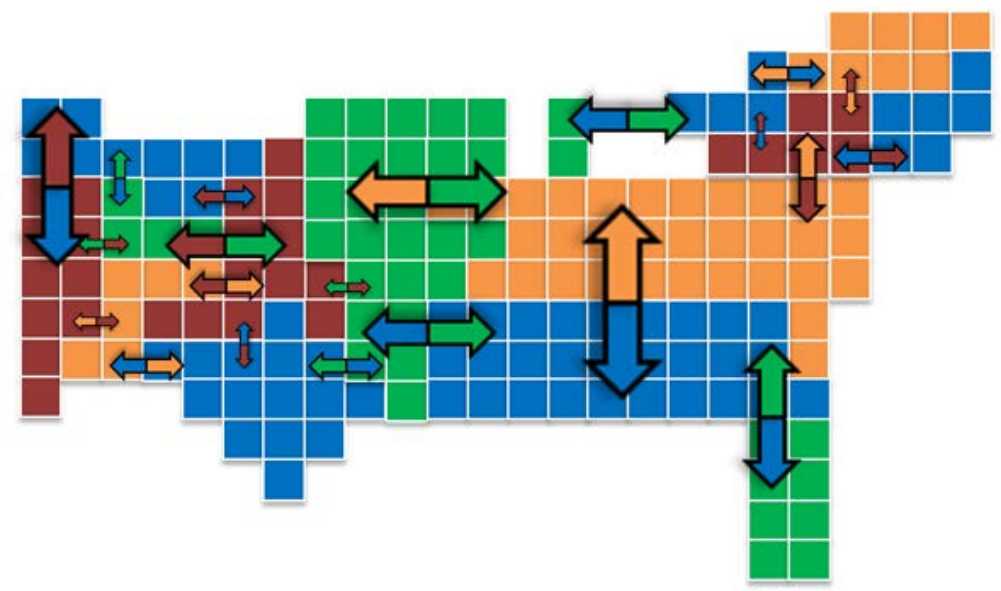

Figure 5. Stage 3: Interconnection-wide optimization of real-time dispatch based on unit commitment from the day-ahead (Stage 2)

\footnotetext{
${ }^{5}$ Note this figure represents the entire U.S., with blocks sized based on peak load for each decomposed region
} 
For the Stage 2 decomposed day-ahead runs, the flow schedules are fixed from Stage 1. The actual optimization does include the transmission network representation of the entire interconnection. However, all loads and generators outside the region are represented with a region-level net generation value, which would be equivalent to a bus-level value in a nodal model.

\subsection{Scenarios}

The scenarios modeled here are based on the ERGIS scenarios and the NREL Regional Energy Deployment System Model (ReEDS) 2016 Standard Scenarios work (Cole et al. 2016). The Standard Scenarios are the results of the NREL ReEDS capacity expansion model for various different suites of assumptions. For this work, we focused on the $80 \%$ National RPS scenario, which had very high penetrations of VG. The modeled scenarios are not projections of future generation technology deployment; but rather, they reflect a plausible geographic distribution of renewable generation technology deployments under the assumption that they collectively reach high penetration levels.

Operational costs are analyzed in the present analysis, but previous and ongoing work have also studied the overall costs (capital and operational costs) of scenarios with high penetrations of renewable generation. For context, Cole et al. (2017) in the NREL 2017 Standard Scenarios report analyze the cost and evolution of high penetration scenarios in detail and include a Midcase scenario that assumes business as usual for the electric grid. The Mid-case scenario models a $45 \%$ penetration of renewable resources in the United States by $2050 .{ }^{6}$ The $80 \%$ National RPS scenario assumes an $80 \%$ penetration of renewable resources by 2050 ; costs for this scenario are approximately 8\% higher than the Mid-case, while carbon emissions are 76\% lower (the MidCase represents a 20\% reduction from today's emissions in 2050, in spite of significant load growth). The Standard Scenarios work and the present analysis both consider standard geographic exclusions when siting the renewable generation, but they do not consider potential challenges associated with such large-scale increases to land use for wind and solar development or transmission.

Table 2 and Table 3 show the renewable portfolios in the Base Scenario. Because we used the ERGIS transmission build (based on the stakeholder-reviewed EIPC process) and using updated knowledge of the operational challenges of these transmission constraints from ERGIS, Standard Scenarios generation portfolios were not directly imported. We limited solar PV penetration in FRCC to approximately 35\% (because ERGIS revealed significant diurnal curtailment at similar penetrations), and we used a regional distribution of wind that was very similar to ERGIS but was scaled to meet higher penetrations. For solar PV penetrations (which were much higher than ERGIS, partly due to the cost of solar having come down since the ERGIS ReEDS runs were done), we assumed a minimum of approximately $20 \%$ annual penetration in every region, with higher penetrations in the southern regions: FRCC, PJM, SERC, and Southwest Power Pool (SPP).

\footnotetext{
${ }^{6}$ For reference, the Energy Information Administration’s Annual Energy Outlook 2018 (EIA, 2018) Reference Case projects 31\% renewable penetration in 2050.
} 
Table 2. Renewable Portfolio in the Base Scenario

\begin{tabular}{lcccc}
\hline & $\begin{array}{l}\text { Wind (\% by } \\
\text { energy, pre- } \\
\text { curtailment) }\end{array}$ & $\begin{array}{l}\text { Solar PV } \text { (\% }^{\text {by energy, }} \\
\text { pre- } \\
\text { curtailment) }\end{array}$ & $\begin{array}{l}\text { Hydro (\% by } \\
\text { energy, pre- } \\
\text { curtailment) }\end{array}$ & $\begin{array}{l}\text { Total Wind } \\
\text { + Solar }+ \\
\text { Hydro }\end{array}$ \\
\hline FRCC & 0.0 & 35.0 & 0.1 & 35.1 \\
\hline ISO-NE & 45.6 & 23.4 & 6.1 & 75.1 \\
\hline MISO & 79.9 & 23.3 & 1.7 & 104.9 \\
\hline NYISO & 50.8 & 23.2 & 16.4 & 90.4 \\
\hline PJM & 38.7 & 27.9 & 0.9 & 67.5 \\
\hline SERC & 3.4 & 28.9 & 3.4 & 35.7 \\
\hline SPP & 153 & 21.4 & 0.8 & 175.2 \\
\hline U.S. Eastern & 46.9 & 26.7 & 2.6 & 76.2 \\
Interconnection & & & & \\
\hline
\end{tabular}

The Base- $75 \%$ scenario is a $10 \%$ increase on all VG.

Table 3. Wind and Solar Capacity in the Base Scenario

\begin{tabular}{lrr}
\hline & $\begin{array}{l}\text { PV Capacity } \\
\text { (GW) }\end{array}$ & \multicolumn{1}{l}{$\begin{array}{l}\text { Wind Capacity } \\
\text { (GW) }\end{array}$} \\
\hline FRCC & 54.9 & 0.0 \\
\hline ISO-NE & 25.1 & 17.2 \\
MISO & 127.2 & 163.6 \\
\hline NYISO & 29.9 & 22.4 \\
PJM & 184.3 & 101.3 \\
\hline SERC & 142.8 & 8.1 \\
SPP & 30.3 & 91.2 \\
\hline Total & 594.4 & 403.9 \\
\hline
\end{tabular}

Reserve requirements in the model were held based on the same methodology used for ERGIS and were adjusted for the scenarios described below. This method adjusts the reserve requirement for every hour of the year based on the short-term uncertainty in wind and solar generation in addition to the load.

\footnotetext{
${ }^{7}$ As was done in ERGIS, $40 \%$ of all PV capacity was modeled as distributed rooftop PV. The profile and capacity factor for these sites are representative of south-facing systems at a tilt of 15 degrees. The impacts on the distribution network are not analyzed in this study, and grid operators are assumed to have the ability to curtail distributed generation when it is optimal. The distribution-level impacts at these levels of penetration is an area that needs further work.
} 


\subsubsection{Base-70\%}

The Base scenario uses the portfolio described in Table 2, with flexible operational assumptions. There is no hurdle rate ${ }^{8}$ and no requirement for thermal or hydropower generation to be online in every region. This assumes any frequency support and voltage stability concerns ${ }^{9}$ that do arise are solved through synchronous condensers, synthetic inertia or active power controls, and other technologies. This scenario also assumes all coal and nuclear generation can be shut down or turned down to minimum generation levels when it is optimal for the system.

\subsubsection{Base-75\%}

The assumptions in the Base- $75 \%$ scenario are identical to the Base scenario, except the VG portfolio is increased by $10 \%$.

\subsubsection{Hurdle Rate-70\%}

This scenario assumes a $\$ 10$ per megawatt-hour (MWh) hurdle rate between the market regions in the day-ahead and real-time simulations (including all stages of the geographically decomposed optimization). This represents friction and inefficiencies that exist between system operators, and it is enforced as a $\$ 10$ increase in the objective function of the optimization for every MW that is transmitted between regions. The extra costs are included in the optimization but not reported directly in the results presented here.

\subsubsection{Must Run-70\%}

This scenario assumes $25 \%$ of the coal and nuclear generation capacity is must-run, and completely inflexible. These must-run units must be online and generating at maximum capacity except during unit outages. Twenty-five percent is approximately the ratio of nuclear to all coal and nuclear capacity today, so this represents a scenario similar to the current flexibility of the coal and nuclear fleets.

\subsubsection{VG Limit-70\%}

This scenario requires that $25 \%$ of all regional load must be served by local thermal or hydro resources. This is enforced at the regional level (FRCC, ISO-NE, MISO, NYISO, PJM, SERC, SPP). Although there is no research to suggest $25 \%$ is a physically meaningful constraint, it has been used as a proxy to represent physical concerns about frequency support, voltage stability, and controllability. Similar requirements were used historically by CAISO (Liu 2014) and as a flexibility limit in the California Low Carbon Grid Study.

\footnotetext{
${ }^{8}$ In the real-time simulations, a small (\$0.50/MW) hurdle rate was applied to prevent major shifts in curtailment (and transmission) between regions that were unnecessary.

${ }^{9}$ Miller et al. (2014) analyzed the frequency response and transient stability of the (western United States) grid at very high wind and solar penetrations. They found nothing to indicate that the grid cannot maintain transient stability at high penetrations, although they noted that more work is needed, and good planning and engineering practices must be followed.
} 


\section{Results}

In this section, we discuss the modeling results of all the scenarios in this study. The renewable penetrations varied from $66 \%$ to $75 \%$ of annual energy, with VG making up approximately $96 \%$ of all renewables; Table 4 shows detailed penetration and curtailment information.

In this study, we analyze the simulated operation of the system in detail, with a focus on indicators of system stress, including utilization of peaking generation, spare online capacity, penetration of synchronous generation, and curtailment. Unless otherwise noted, all results presented are for the U.S. Eastern Interconnection.

Table 4. Summary of Modeled Renewable Penetration (\% of annual energy) in all Scenarios

\begin{tabular}{lcccc}
\hline Scenario & $\begin{array}{l}\text { Renewable } \\
\text { penetration } \\
\text { (modeled) }\end{array}$ & $\begin{array}{l}\text { VG penetration } \\
\text { (modeled) }\end{array}$ & $\begin{array}{l}\text { VG } \\
\text { penetration } \\
\text { (pre- } \\
\text { curtailment) }\end{array}$ & $\begin{array}{l}\text { VG } \\
\text { curtailment } \\
\text { (as a \% } \\
\text { of VG) }\end{array}$ \\
\hline Base-70\% & $70.8 \%$ & $68.2 \%$ & $73.6 \%$ & $7.3 \%$ \\
\hline Base-75\% & $75.3 \%$ & $72.7 \%$ & $81.0 \%$ & $10.2 \%$ \\
\hline Must Run-70\% & $67.8 \%$ & $65.2 \%$ & $73.6 \%$ & $11.4 \%$ \\
\hline VG Limit-70\% & $66.1 \%$ & $63.5 \%$ & $73.6 \%$ & $13.7 \%$ \\
\hline $\begin{array}{l}\text { Hurdle Rate- } \\
\text { 70\% }\end{array}$ & $69.7 \%$ & $67.1 \%$ & $73.6 \%$ & $8.8 \%$ \\
\hline
\end{tabular}

${ }^{a}$ For the sake of consistency with Brinkman (2015) and most renewable portfolio standard policy in the United States, penetrations are listed as a percentage of approximate retail sales.

\subsection{Annual Results}

For the scenarios with flexible operational parameters, we found that curtailment was 7.3\% for the Base-70\% scenario and 10.2\% for the Base-75\% scenario. However, less-flexible operating practices (which could potentially alleviate some of the frequency concerns) led to significantly higher curtailment levels of up to 13.7\%. These scenarios assume frequency support considerations will be addressed without requiring additional thermal generation to be online. These approaches could include synthetic inertia, synchronous condensers, and other technologies. The modeling differences between scenarios include:

- Hurdle rates, which represent friction between neighboring balancing authoritiesthis scenario increased curtailment to $8.8 \%$.

- Must-run resources - twenty-five percent of the $300 \mathrm{GW}$ of coal and nuclear generation capacity were required to be online and unable to ramp down. This led to $11.4 \%$ curtailment.

- Requirements to serve $25 \%$ of load with local thermal resources - this represents concerns about inertia and controllability. Renewables providing spinning and regulating reserves, synthetic inertia, and other grid services could potentially address these concerns, but this scenario represents a "bookend" where these solutions are not physically or institutionally feasible. This scenario led to $13.7 \%$ curtailment. 
Curtailment in these scenarios with less operational flexibility increases approximately $40 \%$ compared to the Base-75\% scenario, which has $74.5 \%$ renewable generation $(71.9 \%$ VG) and has $10.2 \%$ curtailment in the Base scenario. The marginal curtailment ${ }^{10}$ between the Base- $70 \%$ and Base- $75 \%$ scenarios is $34 \%$, indicating that storage, demand response, and other technical solutions to curtailment could be very useful in these scenarios, especially the Base- $75 \%$ scenario. No additional storage and demand response were added to the model for these scenarios. The most useful approaches for reducing curtailment would primarily be solutions that shift energy in time (or space).

The annual generation by generator type in all the scenarios can be seen in Figure 6. The difference in generation by type from the Base scenario can be seen in Figure 7. In the Must Run-70\% scenario, coal and nuclear resources generate more, while gas, wind, and solar resources generate less (leading to more curtailment). In the VG Limit-70\% scenario, both combined cycle natural gas and coal units generate more, leading to more curtailment. Generation differences are much smaller in the Hurdle Rate- $70 \%$ scenario, where additional natural gas combined cycle generation leads to more curtailment.

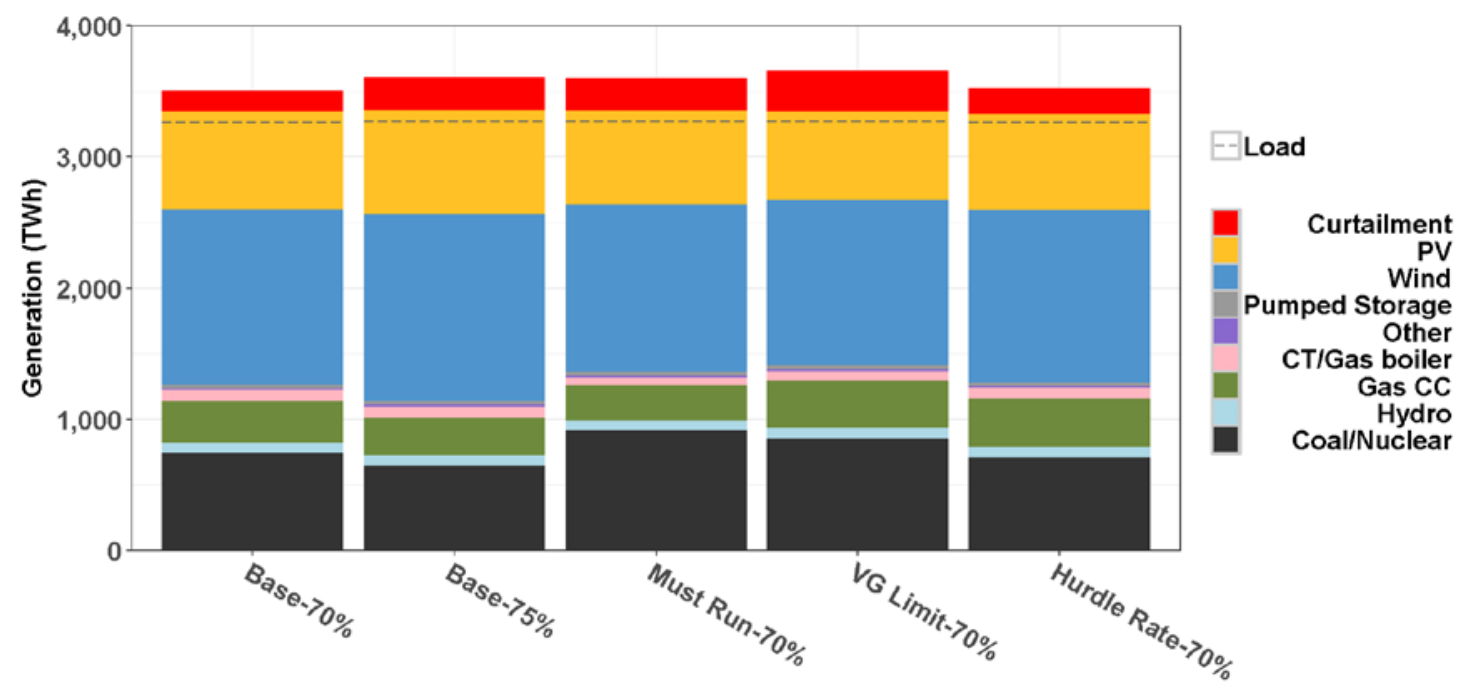

Due to ongoing uncertainty with projecting coal and nuclear generation capacity, we combine these two resources into a single category called "Coal/Nuclear" in reporting for this study

Figure 6. Total annual U.S. Eastern Interconnection generation

\footnotetext{
${ }^{10}$ Difference in curtailment divided by difference in possible renewable generation
} 


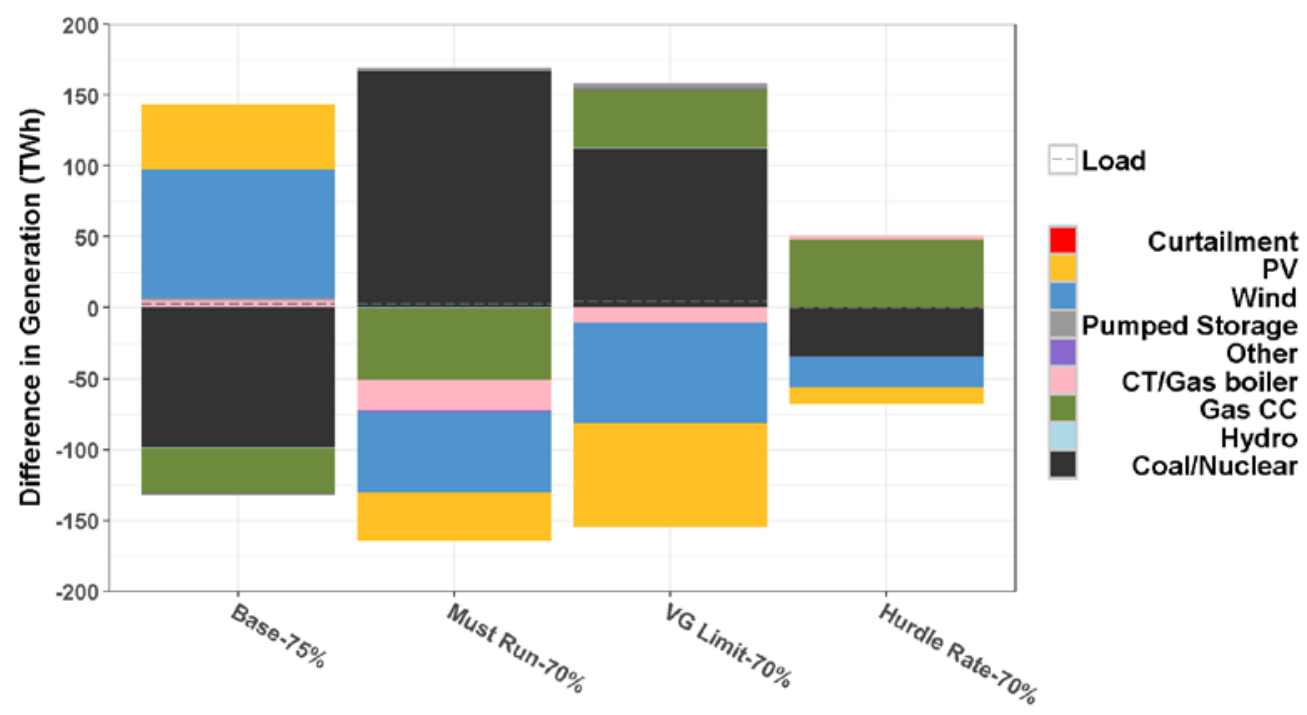

Figure 7. Difference in total annual U.S. Eastern Interconnection generation compared to the Base- $70 \%$ scenario

Figure 8 shows the annual generation by type and region. The horizontal dashed line represents the load in the region, SERC imports a large portion of the generation used to serve load while SPP and MISO are exporters. Thermal generation is still a significant portion of total generation in most regions except NYISO, which has significant hydro resources and ISO-NE, which has mostly VG, and a small amount of hydro and gas in these scenarios. It can also be seen that the bulk of the wind resides in MISO and SPP. PJM, ISO-NE, and NYISO are relatively balanced between wind and solar, while FRCC and SERC are dominated by solar. 

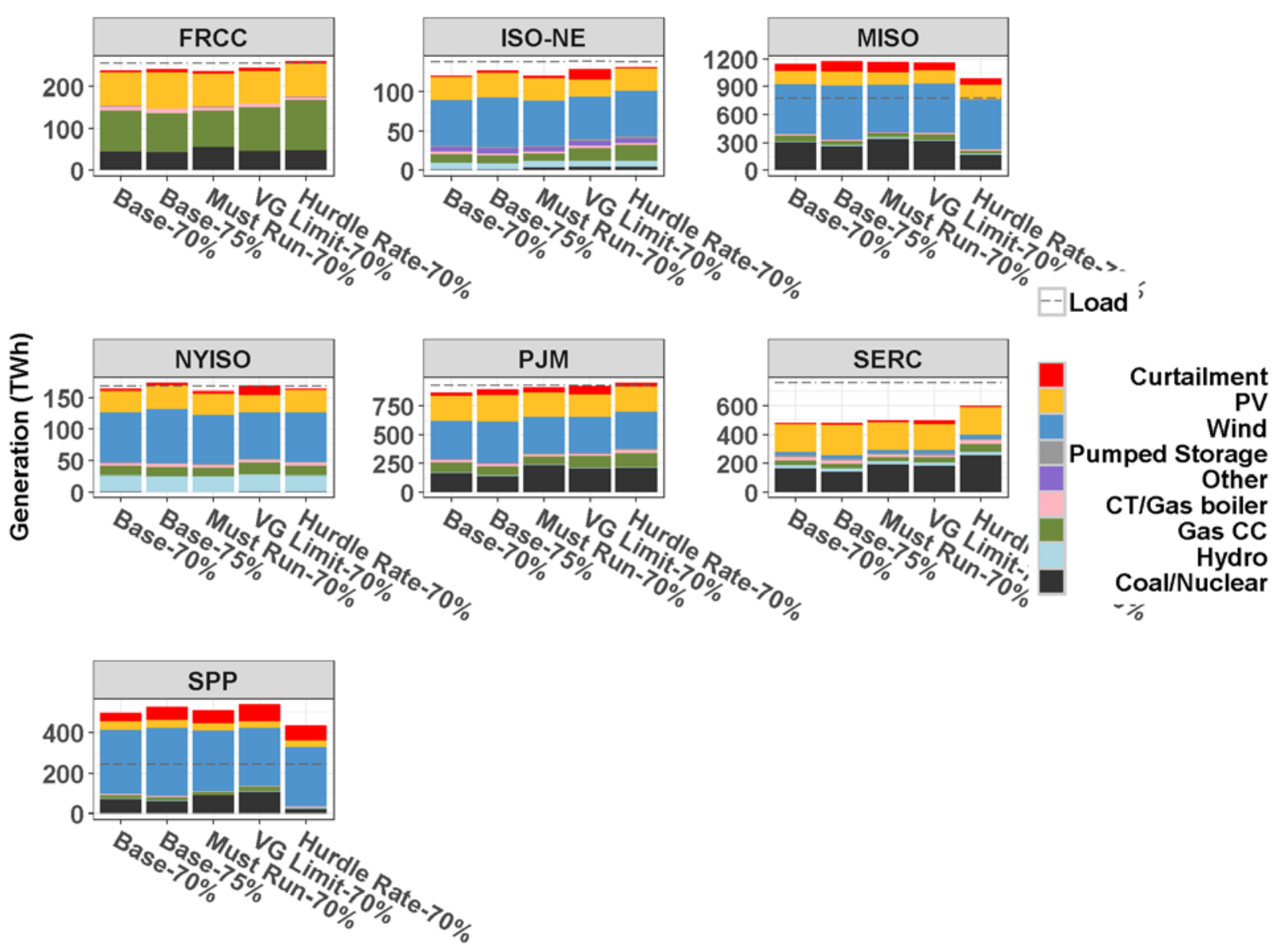

Figure 8. Regional generation for each scenario

Note scale differences.

Most reserves were provided by fossil fuel generation (see Figure 9), including coal and nuclear generators, combined cycle gas, and peaking combustion turbine gas generators. This differs from the Western Interconnection (Brinkman 2015), where most reserves were served by hydro, pumped hydro storage, and concentrating solar power (in addition to wind and solar PV). These resources are less abundant in the East, and the thermal resources are able to fill the void without leading to excess curtailment. Note that wind and solar can only provide regulation up and spinning reserves when they are curtailing generation. 


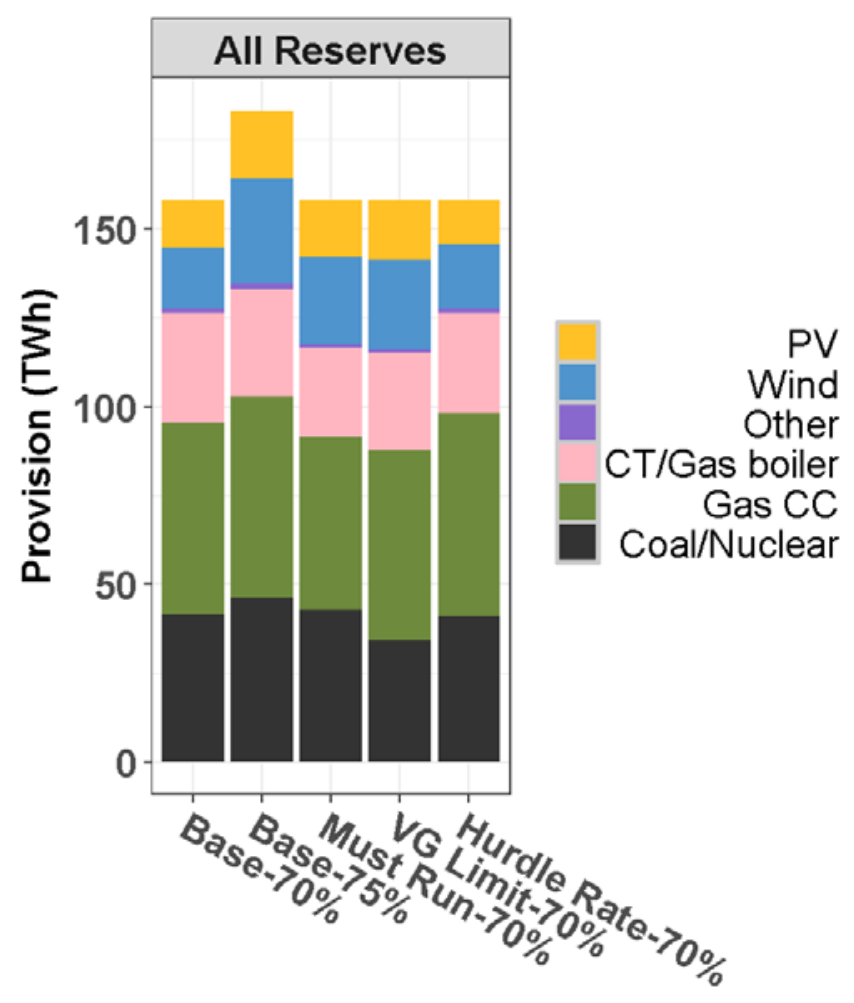

Figure 9. Reserves provided by generator type

Table 5 shows the total production costs by scenario. Production costs are the costs to operate the system, and they do not include the capital costs associated with the deployment of generation and transmission capacity. The scenarios with lowest operational costs are the Base- $70 \%$ and Base-75\%. In general, less VG utilization leads to higher costs as less fuel is displaced. The Base- $75 \%$ scenario is therefore able to displace the most fuel. Of the less-flexible scenarios, the Must Run-70\% case is the least costly to operate, being slightly cheaper than the Hurdle Rate$70 \%$ scenario. The Hurdle Rate-70\% has less VG curtailment but has higher fuel costs because it commits more natural gas combined cycle units than the Must Run-70\% scenario, and the combined cycle plants are more expensive to run than the coal and nuclear units. The VG Limit$70 \%$ and Hurdle Rate-70\% scenarios have the lowest start costs. The VG Limit-70\% requires a certain amount of conventional generation to be online at all times, leading to fewer units cycling on/off. The Hurdle Rate-70\% scenario incentivizes local units to stay online, making each region somewhat more robust to VG forecast errors. The Base-70\%, Base-75\%, and Must Run-70\% scenarios all require quick-start combustion turbines in those situations, leading to higher start costs. 
Table 5. Total Production Costs by Scenario (million dollars)

\begin{tabular}{lccccc}
\hline Type & Base-70\% & Base-75\% & $\begin{array}{l}\text { Must Run- } \\
\mathbf{7 0 \%}\end{array}$ & VG Limit-70\% & $\begin{array}{l}\text { Hurdle } \\
\text { Rate-70\% }\end{array}$ \\
\hline Fuel & 38,913 & 35,148 & 40,820 & 42,980 & 40,509 \\
\hline $\begin{array}{l}\text { Start and Shutdown } \\
\text { Variable Operations }\end{array}$ & 6,439 & 7,014 & 6,101 & 5,239 & 5,913 \\
$\begin{array}{l}\text { and Maintenance } \\
\text { Costs }\end{array}$ & 2,638 & 2,334 & 3,043 & 2,997 & 2,590 \\
\hline Total & 47,990 & 44,960 & 49,964 & & \\
\hline
\end{tabular}

\subsection{System Stress}

Operating the system at such high levels of variable generation will lead to changes in the way thermal generation and transmission are operated. The next section summarizes when the system was under "stress," from either an economical or an operational perspective. While it is unclear today exactly what metrics will be important to operate the grid economically and reliably in a system with high VG penetrations, we propose several metrics that shed light on potential concerns. System stress, as it is defined here, is not necessarily indicative of reliability or longterm economic concerns. However, it does indicate a system that operates differently from the way we have operated in recent decades. For example, curtailment can provide many services to the grid (e.g., flexibility and operating reserves), but it does indicate near-zero marginal prices and other potential stresses that were uncommon in recent decades but have become more common.

Similarly, the operational stress metrics do not necessarily indicate a reliability problem, but they may indicate operation with reliability services (e.g., frequency and voltage support) coming from different sources compared to today. This will require additional study to understand all the implications.

This section is separated into a presentation of potential economic and operational stresses. The economic stress metrics show times when the system cannot utilize all the low-marginal cost resources (e.g., curtailment of renewables). Although curtailment is an excellent source of flexibility and could allow VG to provide essential reliability services, zero-price times can lead to market challenges and long-term revenue sufficiency challenges if market clearing prices remain extremely low. Further study is needed to understand these impacts.

Operational stress metrics attempt to identify times when the power system is operating on tight margins and may not have sufficient flexibility to deal with contingencies or uncertainties. We also include metrics on the instantaneous penetration of VG, which could indicate stress if the renewables are not concurrently providing sufficient quantities of essential reliability services.

The first indicator of stress is the regional prices. Figure 10 shows the price duration curves for each scenario and region. Periods of zero or extremely low prices indicate large-scale VG curtailment. These periods could be economic stressors to the system. First, curtailment means there is emission-free and zero-cost energy not being used by the system. Second, thermal generation that is online during zero-price hours — whether to provide reliability services (as in 
the VG Limit-70\% scenario) or due to their inflexibility (as in the Inflexible Base Load scenario)—could lose money during these periods or require make-whole payments unless the market structure changes such that the reliability services provide adequate remuneration during these hours. Although curtailment can lead to some economic challenges, the ability of the system operator to curtail VG is an excellent source of flexibility in the system.
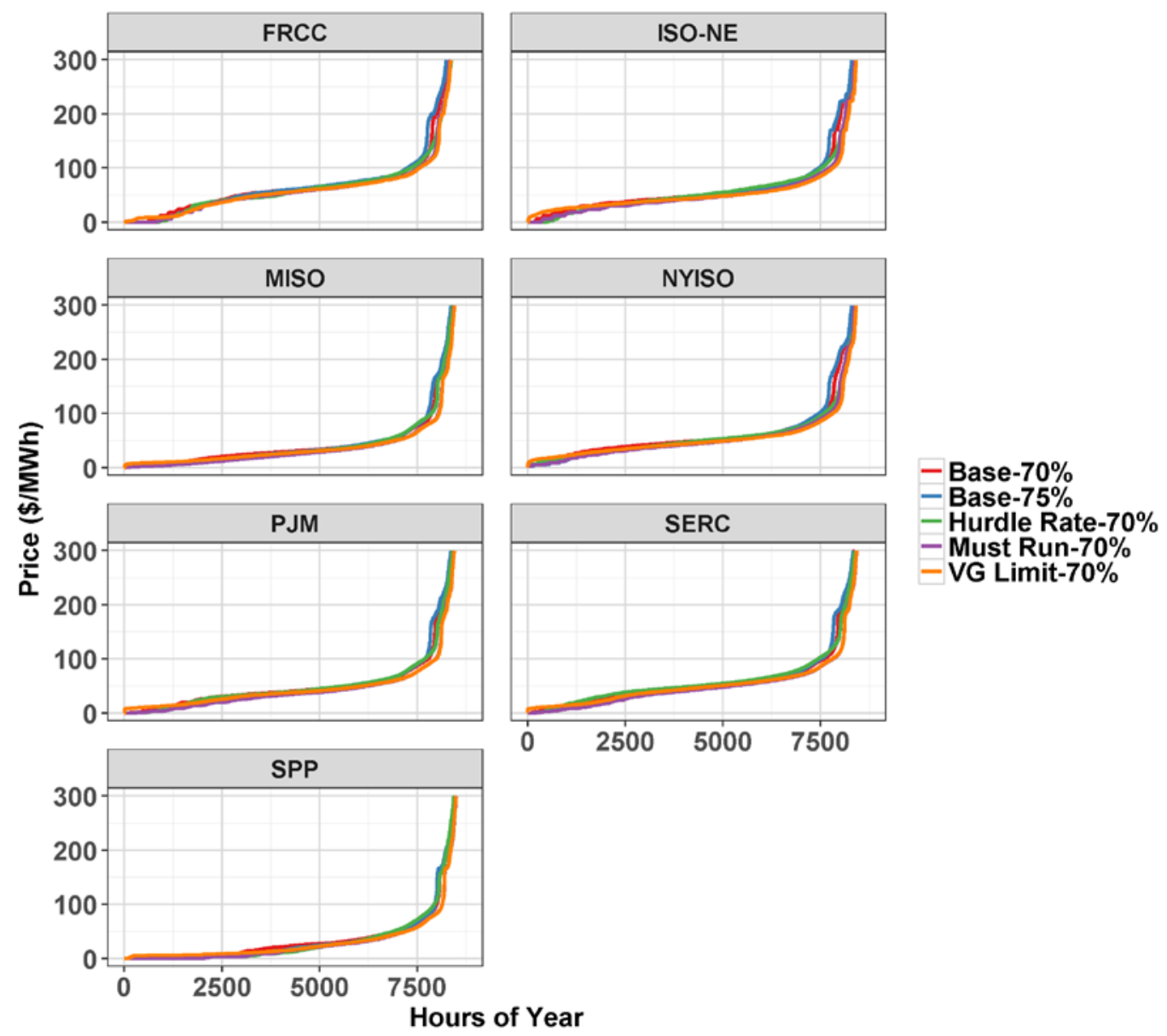

Figure 10. Price duration curve for each U.S. Eastern Interconnection region

Only the bottom 8,300 hours are shown.

Periods of high prices indicate operational stress, or periods where more expensive measures were needed or nearly needed to ensure generation could serve all load. Examples of more expensive measures include commitment of expensive generators and start-up of quick-start generators. Causes of this stress can be high load or net load, VG forecast errors, or large subhourly deviations in the net load from the hourly schedule.

The prices in Figure 10 indicate that for much of the year, the system operates with normal prices or with prices that do not translate to significant system stress. This holds true across all regions and scenarios. Fewer than $25 \%$ of the hours have extremely low or zero prices in most regions; there is widespread curtailment during these times. Fewer than 1,000 hours have prices above $\$ 100 / M W h$ in most regions, which could indicate operational stress. Some of these high prices 
are from small reserve shortages averaged over large areas (see Section 3.2.3). All scenarios have about the same frequency of extreme prices.

\subsubsection{Economic Related Stress (Curtailment)}

Low prices, which indicate economic operation of the system that is different from today, are mostly caused by large quantities of VG available in a high VG system, which leads to curtailment. This section explores curtailment in detail to understand its potential contribution to system stress. Curtailment does not indicate operational stress if the system operator can curtail enough generation, and this provides the grid operator flexibility from these resources. If the operator does not have this control (potentially including high penetrations of distributed generation), overgeneration could lead to frequency problems.

Figure 11 shows a duration curve of VG curtailment throughout the U.S. Eastern Interconnection for each scenario. For more than half the year, VG curtailment is zero or near zero, but for around a quarter of the year, there are tens to hundreds of GW of unused potential wind or solar generation. The Base scenario sees the smallest number of hours with large amounts of curtailment, curtailing more than $50 \mathrm{GW}$ only for 1,000 hours. The VG Limit-70\% scenario curtails more than $50 \mathrm{GW}$ about twice as often as the Base scenario, and it outpaces all other scenarios with the frequency and magnitude of the curtailment.

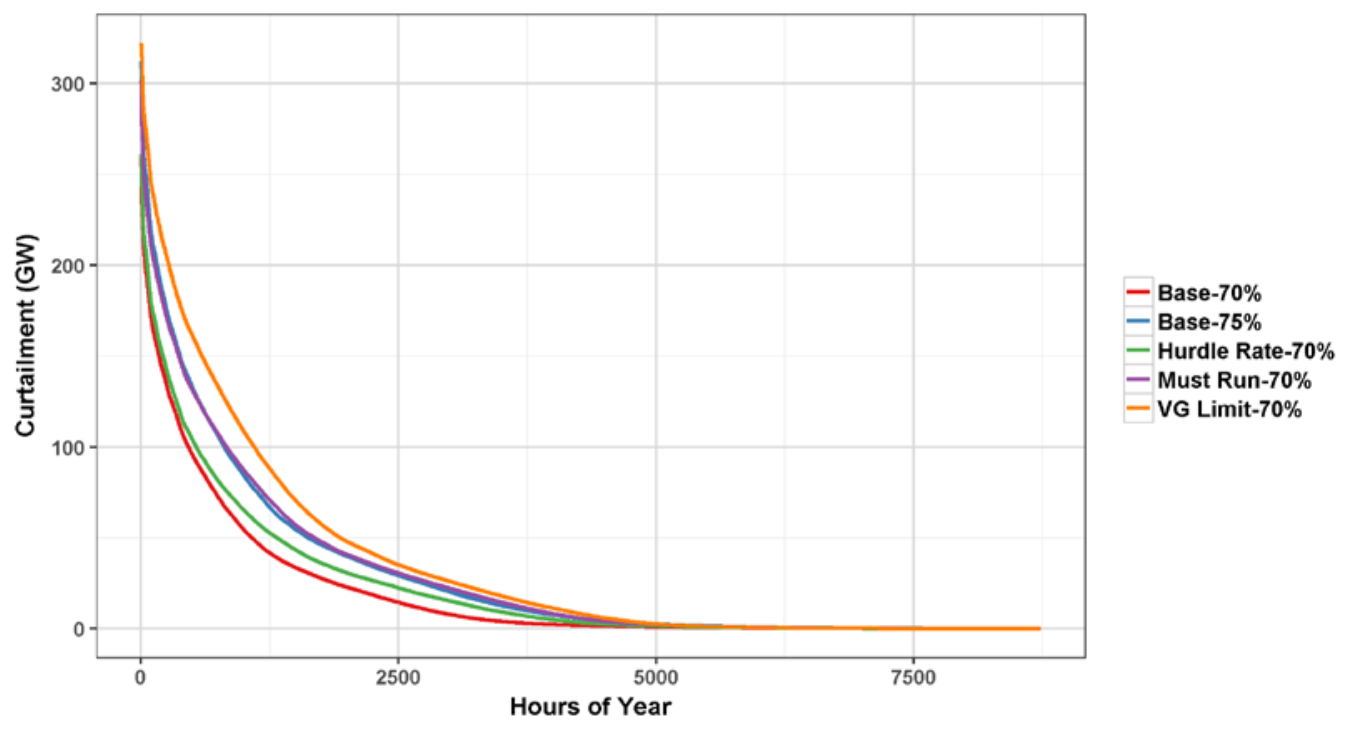

Figure 11. VG curtailment duration curve

As shown in Figure 11, some curtailment occurs in nearly 50\% of the hours, implying zero or near-zero energy prices somewhere in the Eastern Interconnection. There could be market challenges related to these low energy prices. If renewable generators and other nearby generation are receiving little to no compensation for energy (or ancillary services) for close to half of the year, alternate sources of revenue may be necessary for these generators. This could come in the form of other market products or bilateral contracts. 
Figure 12 demonstrates the seasonal pattern to the VG curtailment. The majority of curtailment occurs in the spring and fall months, when load tends to be lowest, but both the wind and solar resources are relatively high. In the Base scenario, 45\% of all curtailment occurs between March and May, which is similar to Brinkman (2015) and suggests a value to seasonal storage to shift curtailed generation in the spring to the summer months. None of the scenarios leads to a change in the distribution of seasonal curtailment.

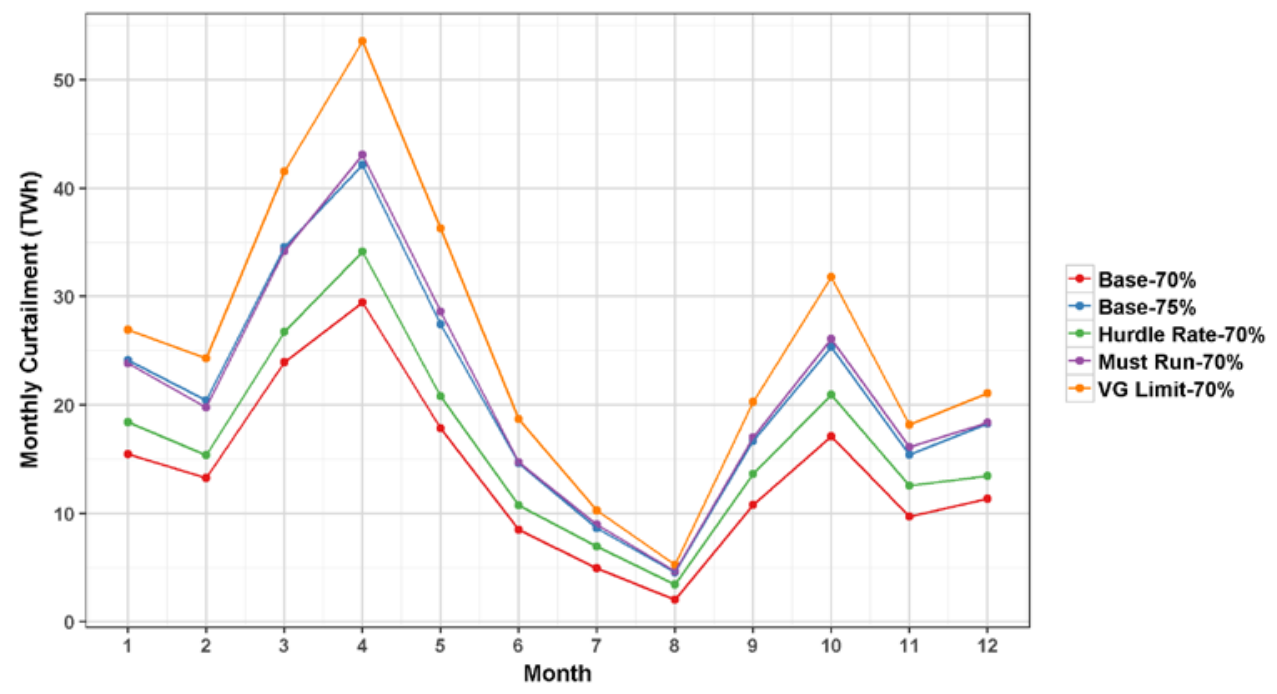

Figure 12. Total VG curtailment for each month

Figure 13 shows the diurnal pattern of curtailment. The vast majority of the curtailment for all scenarios occurs during daylight hours. There is also a small tendency to curtail wind during the early morning hours when load is lowest. The diurnal pattern suggests the use of short-term storage to shift curtailed power to after sunset could reduce the curtailment.

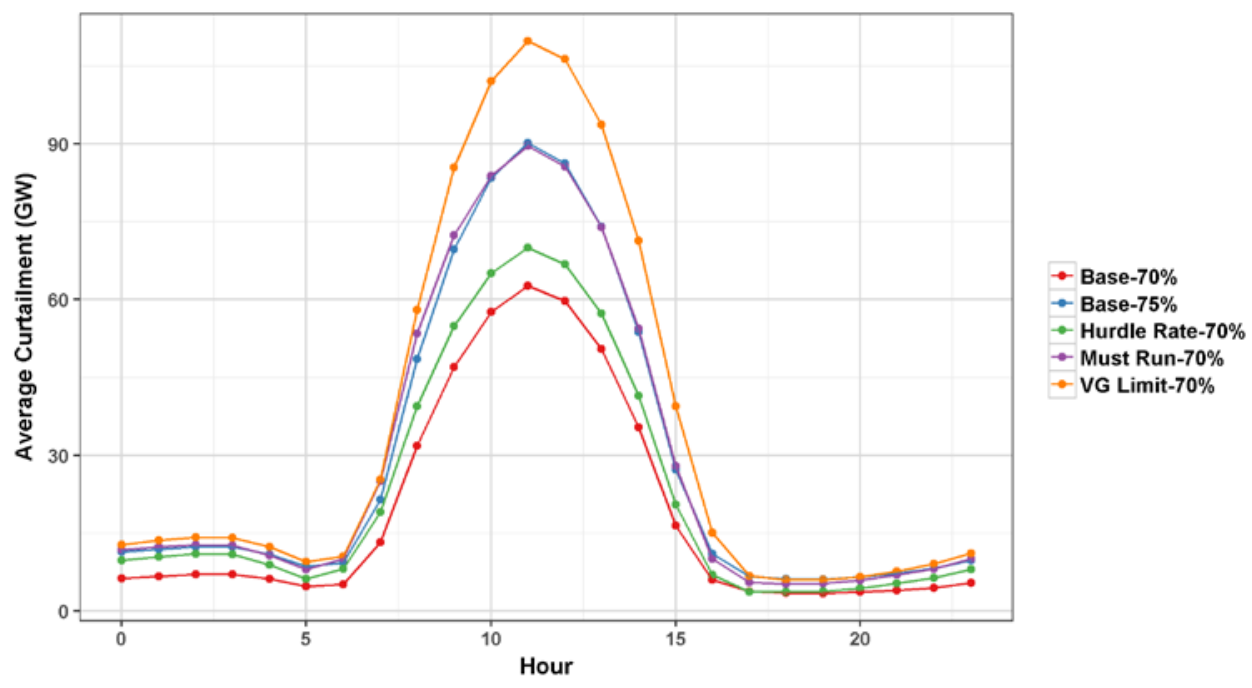

Figure 13. Diurnal curtailment pattern 
High curtailment of renewable energy could indicate economic stress, but it does not necessarily strain the system operations. At the penetrations in this study, a large portion of the curtailment is pre-scheduled in the day-ahead unit commitment, and the curtailment is used to deal with minimum generation at other units, very high instantaneous penetration issues, and transmission congestion. The curtailment in the day-ahead will be scheduled in hourly time blocks, just as with the commitment of thermal units and hydro generation.

The red-line is a 1:1 line.

Figure 14 (next page) shows the correlation between the pre-scheduled curtailment and the actual hourly curtailment. The red line on the plot for each scenario is a 1:1 line. If the pre-scheduled curtailment perfectly predicted actual curtailment, all points would fall on the line. The actual curtailment tends to be slightly larger than the pre-scheduled curtailment, as can be seen by the higher density of points above the red line. This is mostly due to the five-minute variability that can lead to additional curtailment. But in general, the pre-scheduled curtailment offers an accurate estimate of what the actual curtailment will be, in all scenarios. Table 6 shows the portion of the actual curtailment that was not forecast in the day-ahead simulation in each scenario.

Table 6. Curtailment Scheduled in Day-Ahead

\begin{tabular}{lc}
\hline Scenario & $\begin{array}{c}\text { \% of Curtailment Unexpected } \\
\text { based on Day-Ahead }\end{array}$ \\
\hline Base-70\% & $37 \%$ \\
\hline Base-75\% & $33 \%$ \\
\hline Must Run-70\% & $37 \%$ \\
\hline VG Limit-70\% & $26 \%$ \\
\hline Hurdle Rate-70\% & $40 \%$ \\
\hline
\end{tabular}



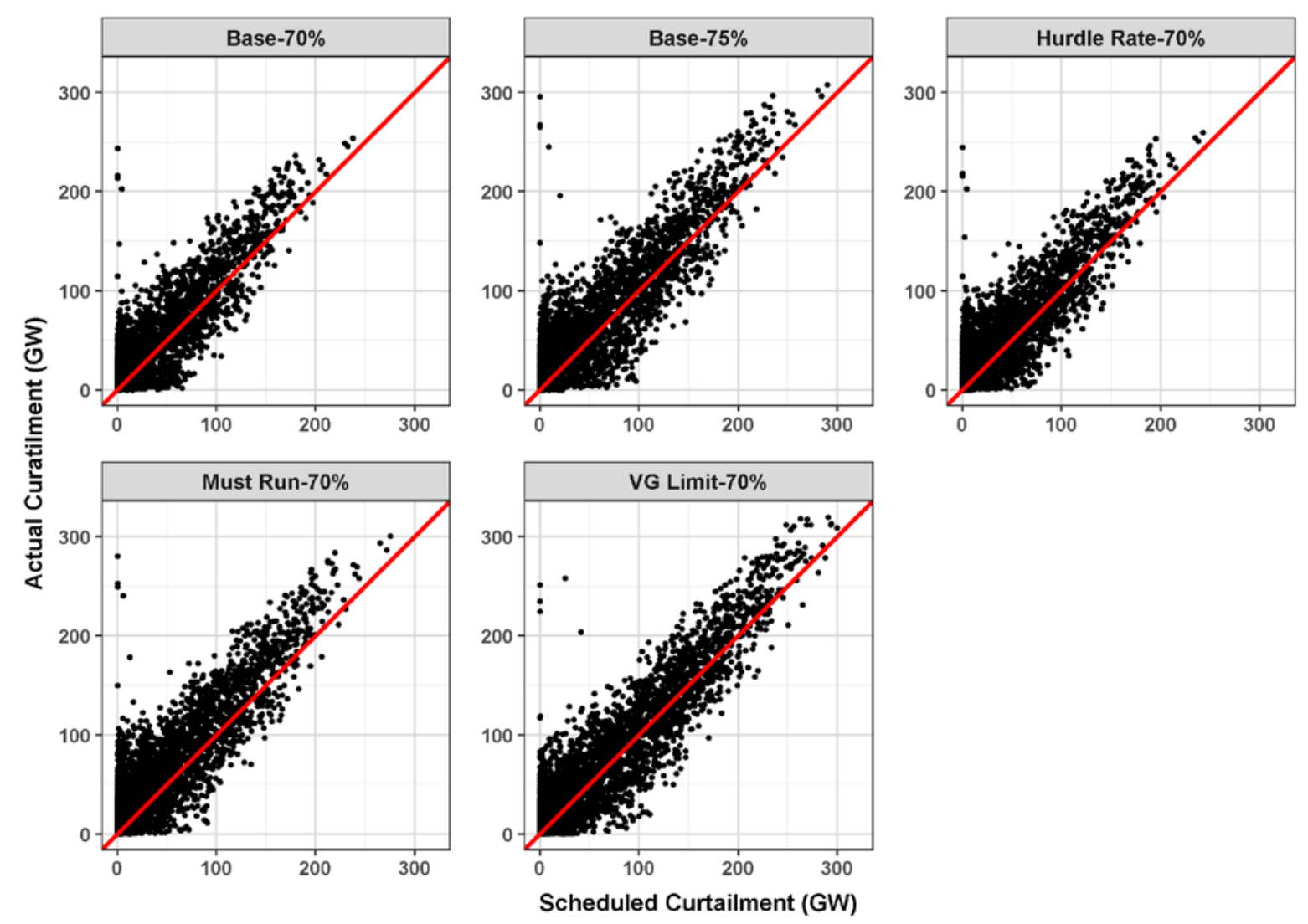

The red-line is a 1:1 line.

Figure 14. Curtailment compared to the amount of curtailment scheduled in the Day-Ahead Unit Commitment step

However, correctly predicting curtailment is not the goal of system operators. Curtailment can change based on forecast errors for the available energy from wind or PV, even if some of that energy would be curtailed. To understand whether that curtailment will cause stress to system operations, The red line is a 1:1 line.

Figure 15 shows the correlation between actual VG generation over an hour and the scheduled hourly generation. The data lie near the 1:1 to line, indicating that scheduling VG in the DA is reasonably accurate. This suggests relatively low operational stress from curtailment and forecast errors on an hourly basis. 


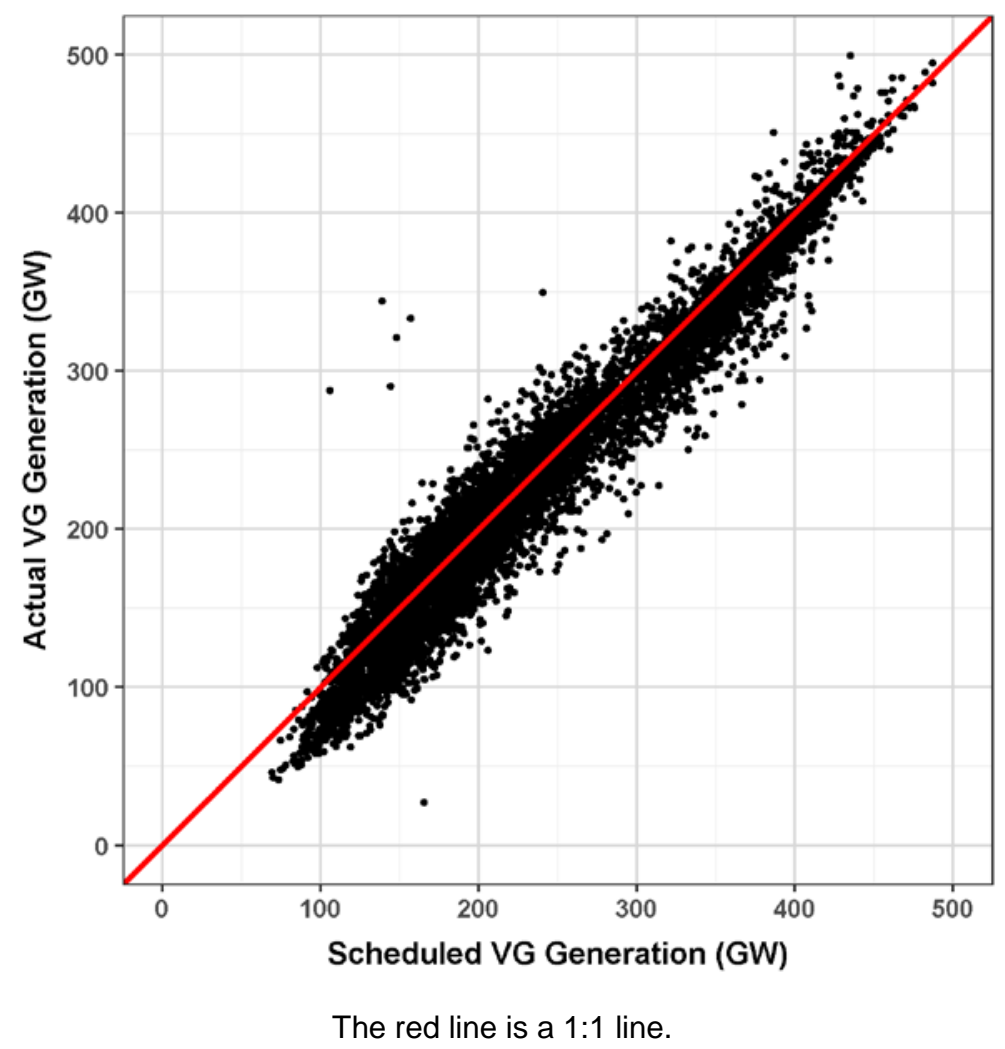

Figure 15. Hourly VG generation compared to hourly scheduled VG generation in the Base scenario

However, the difference between the actual VG generation and scheduled VG generation is more severe when we drill down to the five-minute level. As mentioned earlier, VG generation and curtailment are block-scheduled over the hour during the day-ahead unit commitment step. But the economic dispatch period of this model is done at five-minute resolution. The red line is a 1:1 line.

Figure 16 shows how the correlation between actual VG generation and scheduled generation changes when we consider the actual generation at the five-minute level. The data still largely lie along the 1:1 line, as expected given the hourly aggregation in The red line is a 1:1 line.

Figure 15, but the spread around the 1:1 line increases at the five-minute level. The points that diverge more from the 1:1 line can increase operational stress, even if the hourly scheduled generation matches closely to the hourly actual generation. 


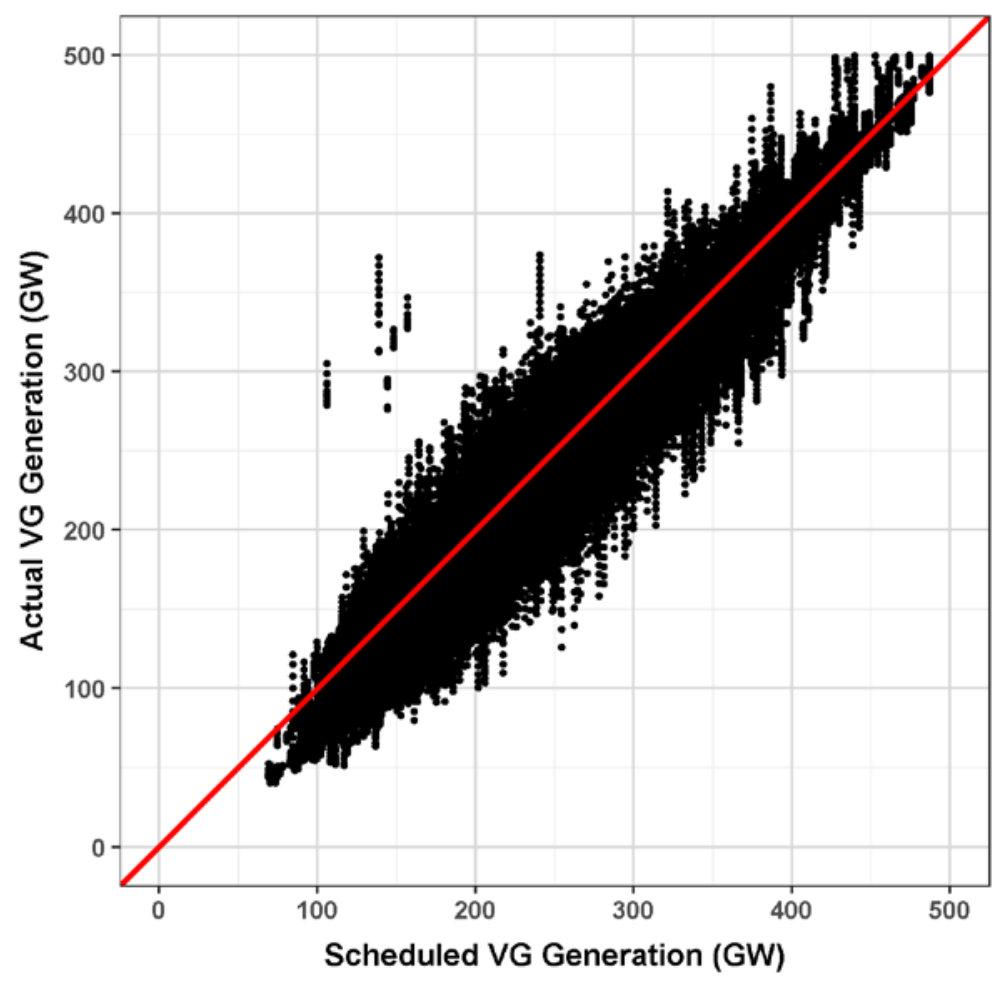

The red line is a 1:1 line.

Figure 16. Five-minute VG generation compared to hourly scheduled VG generation

\subsubsection{System Operations Related Stress}

As stated earlier, system operations stress usually suggests expensive measures were needed to deal with operational issues, such as load balancing, ramping, and forecast errors. High prices seen in the price duration curve in Figure 10 indicate these stresses. Another indication of possible operational stress is low spare online thermal capacity. Spare online thermal capacity is the difference between a thermal generators maximum capacity and its current power output. It provides an indication of how much the net load could increase before idle capacity would need to be started up. Note the system's ability to use the spare online thermal capacity is limited by each generator's ramp rate, but that is not considered for this discussion. Although up-reserves can be provided by a variety of sources, including VG, we provide this analysis for comparison with typical operation in power systems today. Additional analysis of a similar metric, including VG spare capacity is also discussed later in this section.

Figure 17 shows the duration curves of spare online thermal capacity, normalized to the load at that interval. A low percentage of spare online thermal capacity means the thermal fleet is operating near its maximum capacity and could need to start quick-start generation, such as a combustion turbine (CT), to deal with large and unexpected increases in the net load. The system is at risk of requiring an expensive measure to balance the system, indicating system stress. On the other hand, a high percentage of spare online thermal capacity means the system can use its online generation to deal with increases to the net load and is a more stable state to deal with such a disturbance. 

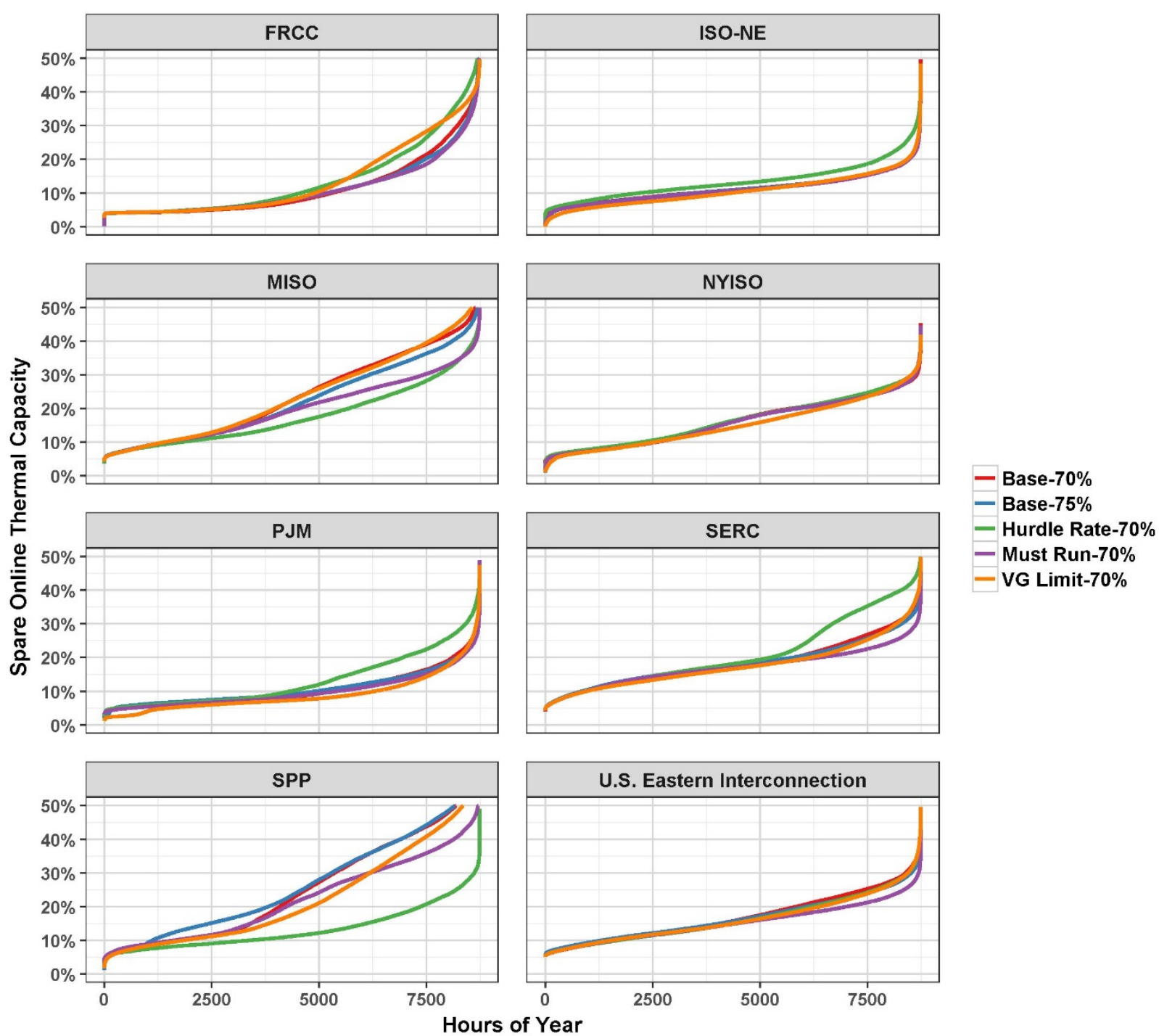

Figure 17. Duration curve of spare online thermal capacity, including capacity used for reserves

For scenarios other than the Hurdle Rate- $70 \%$ scenario, most of the regions operate with similar levels of spare online thermal capacity. For the entire U.S. Eastern Interconnection, the Must Run-70\% scenario operates with the least spare online thermal capacity, although at the lowest spare online thermal capacity levels (on the left portions of the plots above), it is indistinguishable from the other scenarios, except for the Hurdle Rate-70\%.

FRCC, ISO-NE, and PJM tend to operate with tighter spare online thermal capacity (i.e., a lower percentage). These regions are slightly net importers in all scenarios, with the exception of the Hurdle Rate-70\% scenario. This suggests their local generation is on the margin and is not being constrained by the amount of local reserves they must hold to keep thermal units operating. Therefore, their thermal fleets are operating as close to maximum capacity as they can, while holding all reserves. This in turn leads to lower spare online thermal capacity and operations that are at greater risk to disturbances. The risk may be exacerbated by their reliance on imports. SERC is also a net import, but on a much larger scale, importing over a third of its power in all five scenarios. Figure 17 shows SERC operating with more spare online thermal capacity than 
the other importing regions. This suggests much of their thermal fleet is operating well below maximum capacity and is likely constrained to remain on only to provide local reserves. While SERC relies heavily on imports in this study, it maintains significant spare online thermal capacity that could deal with significant disturbances to the net load, indicating stable operations.

MISO and SPP operate with large spare online thermal capacity for much of the year. These two regions are large net exporters across all scenarios, and together, they have more than half of all the potential VG generation in the Eastern Interconnection. These factors lead to a large amount of spare online thermal capacity in many periods and some robustness in the operations to large disturbances.

NYISO is unique in why it has large spare online thermal capacity; it has the largest proportion of hydro generation used to meet its load, along with significant contributions from wind and PV. NYISO also has very little thermal generation in these 2050 scenarios. The thermal generation that it does have is largely online to provide reserves and is therefore online to provide spare online thermal capacity.

Figure 18 shows a similar metric, including all spare online capacity (including VG spare capacity; i.e., curtailment). This is a more complete view of total system spare online capacity to handle changes in net load, and the combination keeps the spare online capacity above the minimum reserve requirements (which varies hourly but is usually above $5 \%$ of the load). When the system has the least spare online capacity (the left side of each panel), in general the numbers look very similar to those in Figure 17, meaning that during these times of low spare online thermal capacity, not much VG spare capacity is available to help relieve system stress. The VG does help in certain regions during low spare online capacity hours (e.g., PJM), when VG is clearly contributing to reserve requirements.

The pattern of spare online capacity throughout the year is not significantly impacted by scenario, meaning the operational challenges studied (generator flexibility, instantaneous VG penetration limits, and hurdle rates) do not reduce or increase the stress associated with low spare online capacity. 

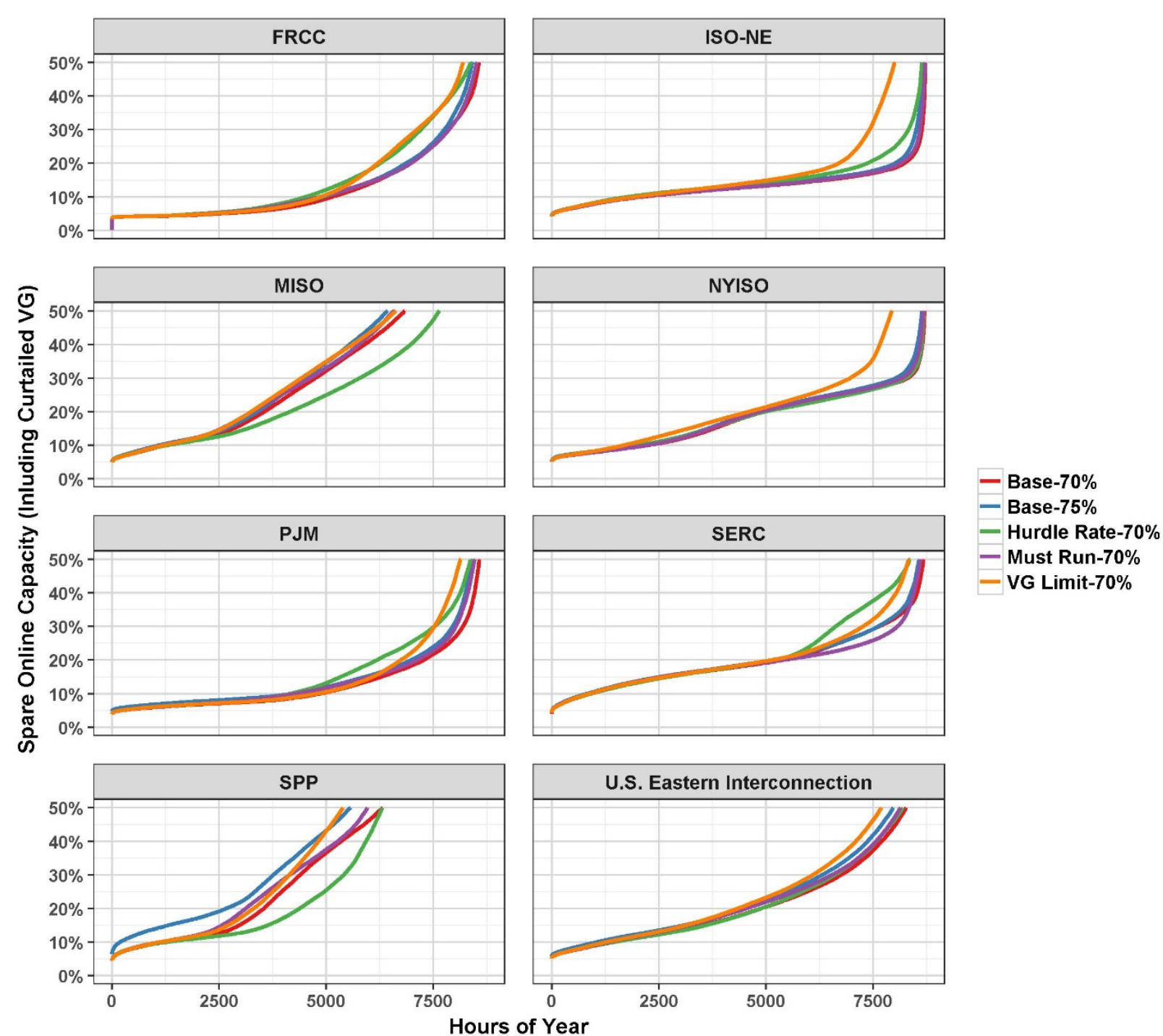

Figure 18. Duration curve of spare online capacity (thermal and VG curtailed capacity)

Another sign of operational stress is the non-synchronous penetration on the system. This metric refers less to balancing stress and more to concerns about low levels of synchronous inertial response on the system. Non-synchronous generators can provide frequency support to the grid (Miller et al. 2014), so this metric shows how often and how much might be necessary in the different scenarios. The frequency support provided by modern inverters has different properties from existing generators, and more work is needed to understand grid operations in conditions with very high non-synchronous penetration conditions. Figure 19 shows the duration curve for non-synchronous penetration on the system. The non-synchronous penetration calculated here is similar to the metric presented in both the Low Carbon Grid Study and Barrows et al. (2018); the generation from wind and solar is divided by the sum of the online capacity of non-inverterbased generators (thermal and hydro) and the generation from wind and solar. In the U.S. Eastern Interconnection, all scenarios stay below 75\% non-synchronous penetration for all but 1,000 hours of the year. The VG Limit-70\% scenario maintains the lowest non-synchronous penetration given that it forces $25 \%$ of all generation to come from non-inverter based 
generators. The Must Run-70\% scenario also limits the highest non-synchronous penetrations seen in the other three scenarios, but it has similar non-synchronous penetrations to the Base scenario for much of the year. Future work is needed to determine what levels on nonsynchronous penetration are concerning based on region size, topology, and other parameters.
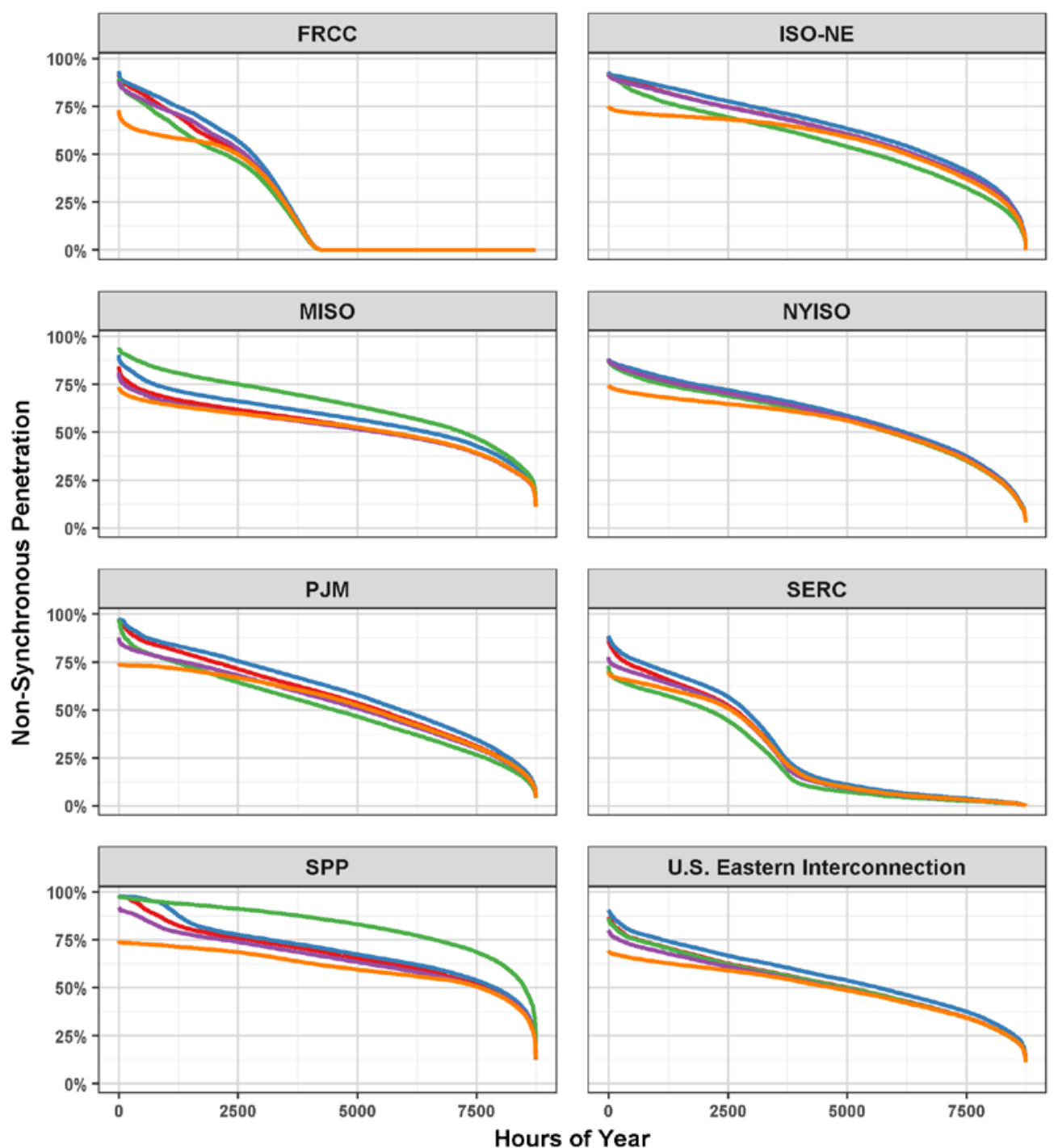

Figure 19. Duration curve of non-synchronous generation on the system.

In contrast to the spare online capacity metrics, this analysis shows that the instantaneous penetration stress metric is substantially impacted by the flexibility sensitivities we studied. The Must Run-70\% and VG Limit-70\% scenarios led to fewer hours with very high penetrations of inverter-based generation. While the challenges increase curtailment, this curtailment mostly occurred at times with very high penetrations of VG.

One way system operators deal with operational stress, particularly when spare online thermal capacity is low, is to start quick-start gas combustion turbines. Figure 20 shows the total capacity started throughout the one year of simulation for coal and nuclear, combined cycle, and gas combustion turbine generators. The total capacity started for CTs is higher than any other 
thermal generator type across all scenarios, but there are large differences in the reliance on quick-start generation between the scenarios. The Base-70\% and Base-75\% scenarios have a similar number of CT starts. The scenarios assume the same amount of thermal, hydro, and transmission flexibility. The Hurdle Rate-70\%, Must Run-70\%, and VG Limit-70\% scenarios reduce the CT capacity start-ups by up to $20 \%$. These scenarios have more coal, nuclear, and combined cycle units online, reducing the need for CT starts.

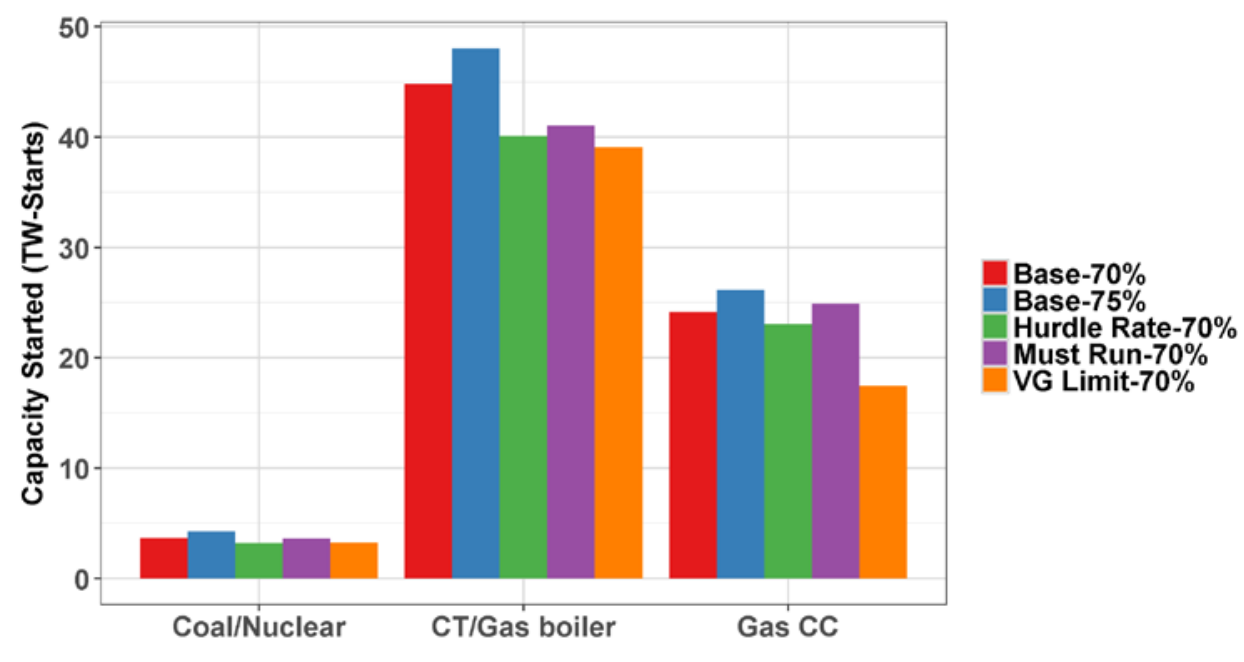

Figure 20. Annual capacity started for coal and nuclear, natural gas combined cycle units, and gas combustion turbines

Figure 21 illustrates when during the day the CTs are started up and therefore indicates when operational stress is at its greatest. All scenarios show the same average diurnal pattern of CT starts. The only difference is the magnitude of the starts. Starts are clustered almost entirely to the periods before/during sunrise (as load picks up but PV is not yet online) and during/after sunset (when load is still high, but PV is ramping down).

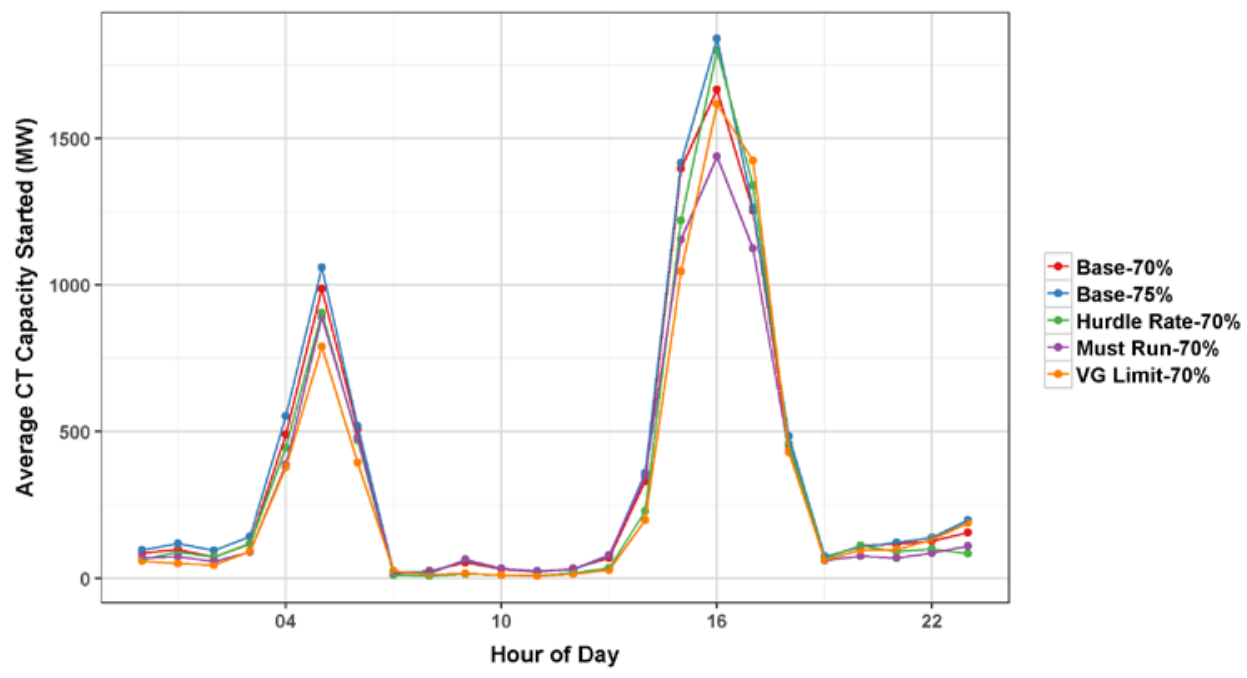

Figure 21. Diurnal pattern of CT starts 
Sunrise is a unique sign of operational stress and one that is likely due to hourly day-ahead commitments enforced on five-minute real-time operations. These CTs are not used for very long, as they shut down within an hour as PV generation picks up, but they are needed to fill the gap of combined cycle units that were shut-down for the middle of the day. Staggering the decommitment of those units or having greater resolution in the unit commitment in the sunrise hours would reduce the need for quick-start CT start-ups.

Sunset may also benefit from subhourly scheduling of combined cycle units to reduce the reliance on CTs during these hours. However, CTs turned on during sunset are more likely to stay on longer to generate during peak net load, and occasionally more CTs are started later in the evening hours, potentially due to wind forecast error. Storage installed with these significant PV levels could potentially help mitigate the need for CT capacity and generation.

Some gas CT usage is scheduled in the day-ahead, which could indicate less stress for the system. The red line is a $1: 1$ line.

Figure 22 shows the correlation between generation from CTs in the real-time economic dispatch and the scheduled CT generation in the day-ahead unit commitment. All scenarios except the Hurdle Rate-70\% scenario show some correlation between scheduled and actual generation, particularly when a large amount CT generation was scheduled in the DA. However, much of the data shows little correlation between the scheduled and actual generation. The data points along the y-axis, at higher actual generation values show times when the system did not expect any CTs were needed to balance the system, but instead tens of GW of quick-start generation were called on in the real-time dispatch. As noted in previous sections, the day-ahead commitment predicted VG curtailment, and especially VG generation, fairly well. However, it did not predict CT usage in relative terms nearly as well. In absolute terms, however, the interconnection-wide difference between forecast and dispatch for both CTs and VG generation were more similarusually within 10-20 GW. More study, potentially looking at the benefits of intraday recommitment using representative intraday forecasts, is needed on this issue. 

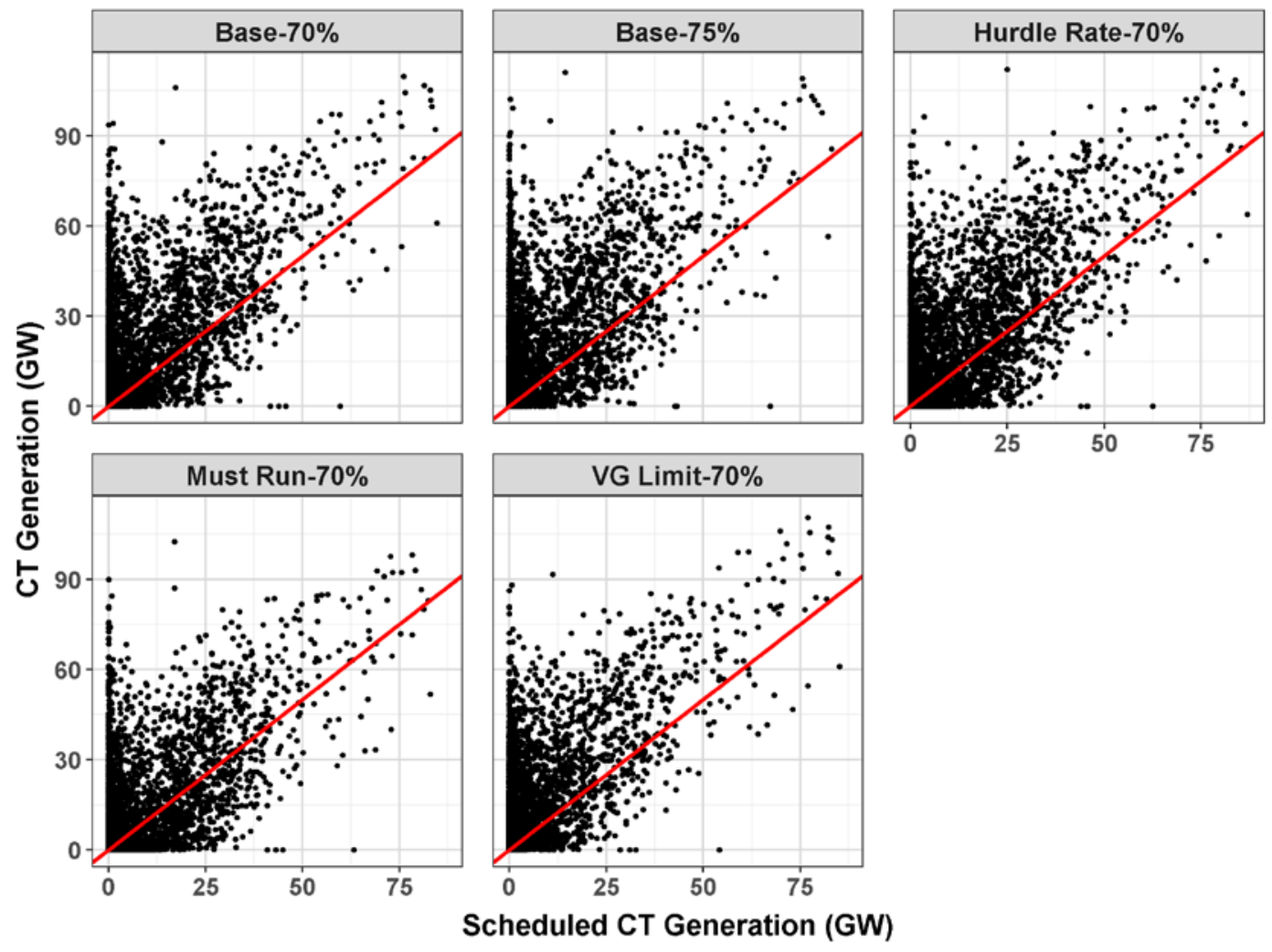

The red line is a 1:1 line.

Figure 22. Real-time CT generation vs day-ahead scheduled CT generation

\subsubsection{Reserves}

Another potential metric of system stress is the ability to serve load and reserves. Reserves are held based on the method from ERGIS, which requires more reserves to be held for renewables, based on short-term uncertainty in renewable generation levels. Table 7 shows the reserve deployment by scenario. Although there were some differences between scenarios (Hurdle Rate$70 \%$ had the lowest reserve shortage), more than $99.99 \%$ of reserves were served in all scenarios. This demonstrates that sufficient capacity is available and committed to serve the load and handle typical contingency events, including forecast errors. 
Table 7. Reserve Deployment by Scenario

\begin{tabular}{lccccc}
\hline Type & Base-70\% & Base-75\% & Must Run-70\% & VG Limit-70\% & $\begin{array}{c}\text { Hurdle Rate- } \\
\mathbf{7 0 \%}\end{array}$ \\
\hline $\begin{array}{l}\text { Reserves } \\
\text { required (GW-h) }\end{array}$ & 158,000 & 183,000 & 158,000 & 158,000 & 158,000 \\
\hline $\begin{array}{l}\text { Reserve shortage } \\
\text { (GW-h) }\end{array}$ & 12 & 16 & 12 & 15 & 3 \\
$\begin{array}{l}\text { Percentage of } \\
\text { reserves served }\end{array}$ & $99.99 \%$ & $99.99 \%$ & $99.99 \%$ & $99.99 \%$ & $99.99 \%$ \\
\hline \begin{tabular}{l} 
Unserved energy \\
\hline
\end{tabular} & 0 & 0 & $\begin{array}{c}0.4 \text { gigawatt- } \\
\text { hours }\end{array}$ & 0 & 0 \\
\hline
\end{tabular}

Although the model did drop 408 MWh of load in the Must Run-70\% scenario, it was primarily a modeling artifact due to a large day-ahead forecast, mixed with the rigid modeling framework that had no intraday decision-making for reliability purposes. Auction-based market regions and vertically integrated utilities both typically have some sort of intraday reliability assessment or decision-making. The $408 \mathrm{MWh}$ were dropped during a single hour in FRCC, and several gas combined-cycle generators were scheduled to start during the following hour based on the dayahead unit commitment. Modeling confirmed that starting those combined-cycle generators one hour earlier (when the forecast error would have already been seen by the system operator) eliminated all the unserved load. This indicates that intraday decision-making will be important in system operation and modeling of future high-penetration scenarios.

\subsection{Key Periods}

This section contains five-minute dispatch plots for key periods, as defined by ERGIS (Bloom et al. 2016). These include a high load, the highest instantaneous penetration of VG, and the highest net-load ramp (which also included a significant over-forecast of wind). Here, we point out some of the stress metrics described in the previous section. These signs of stress include VG curtailment, low spare online thermal capacity, high non-synchronous penetration, and quickstart generation start-ups. These metrics do not necessarily indicate economic or reliability problems, but they do indicate when the grid may need to operate differently than it has in the past.

\subsubsection{High Load Period}

The period between July 29 and July 31 is one of the highest load periods in the U.S. Eastern Interconnection in the simulation. On July 31, the load peaks at about $600 \mathrm{GW}$ on the system. Large portions of the thermal generation fleet are online along with renewables during this multiday period. Figure 23 shows dispatch plots during the period. Curtailment (red) is generally low during the period, as much of the potential VG can be consumed. However, even during this high load period, some curtailment still occurs every day around the peak PV periods. During these mid-day hours with peak PV, there is also noticeable export to Canada (i.e., generation is higher than load). 


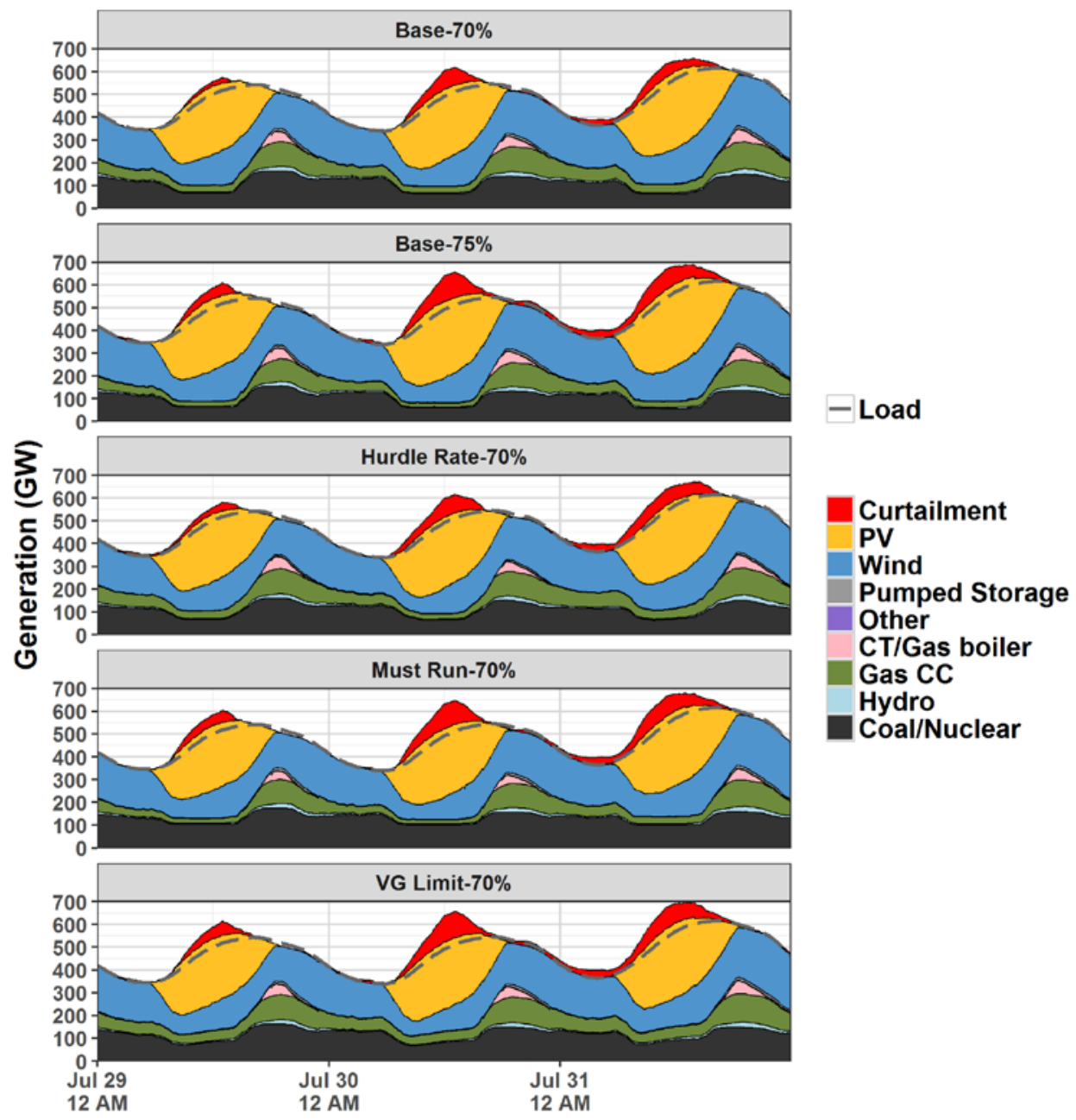

Figure 23. U.S. Eastern Interconnection peak load period

Figure 24 shows the available capacity and generation levels for coal and nuclear, natural gas combined cycle units, gas CTs and boilers, wind, and PV. The coal and nuclear, combined cycle generators, and gas boilers are committed in the day-ahead, meaning their available capacity cannot change during real-time operations. 


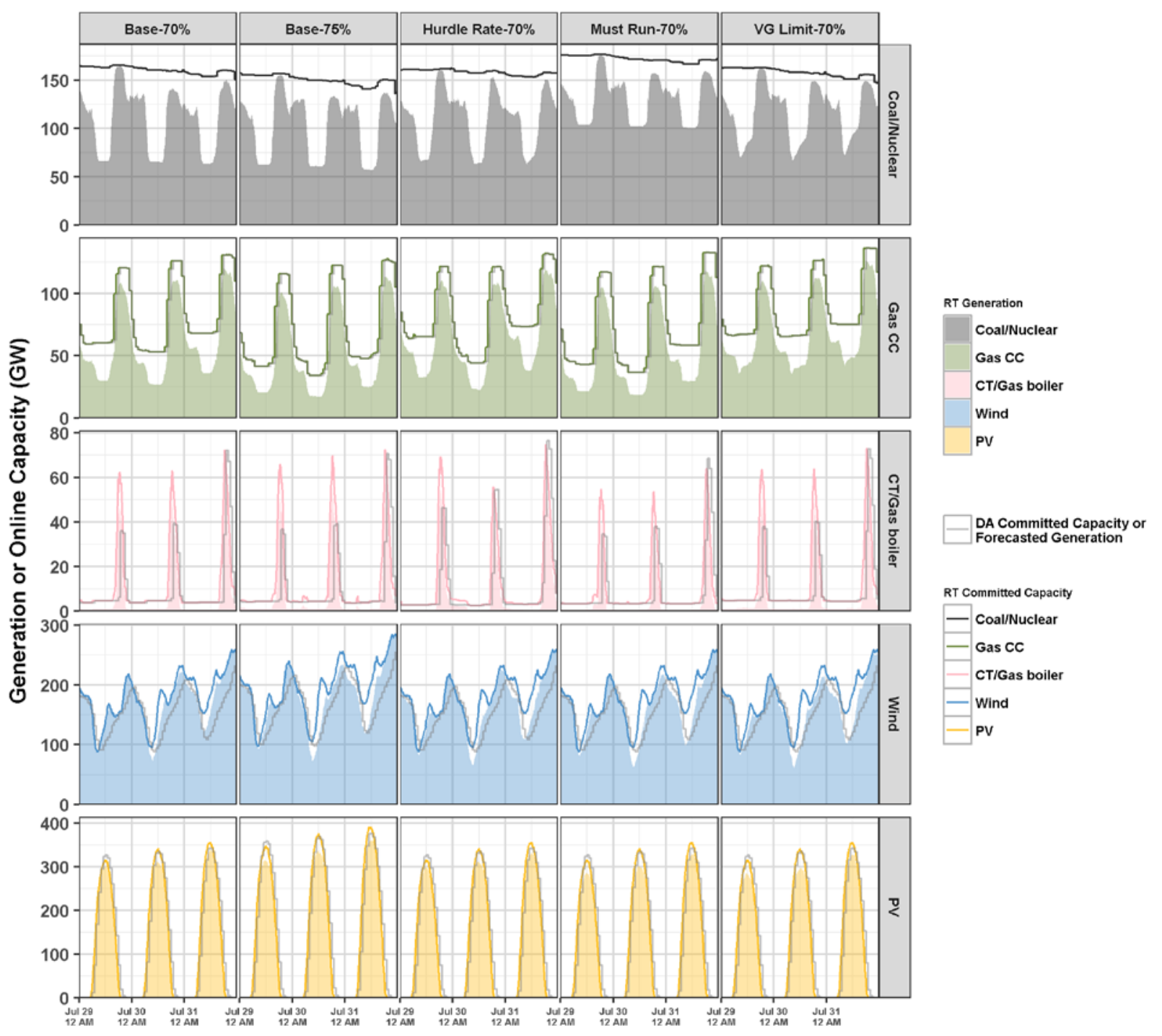

Figure 24. Commitment and dispatch during U.S. Eastern Interconnection peak load period

During the high load period, wind and PV generation do not show large forecast errors. Wind is slightly under-forecast and portions of this under-forecast are curtailed. Coal and nuclear commitments are stable and similar between all the scenarios; generation from coal and nuclear is ramped down during midday as the VG peaks. During these times, many coal and nuclear units are operating at their minimum generation level (which is higher in the Must Run-70\% scenario, where $25 \%$ of the capacity must run at rated capacity). Combined cycles are cycled both on/off and ramped up/down between the daytime/nighttime hours and peak. Because many thermal generators are committed during these peak days, the constraints in the VG Limit-70\% scenario do not affect dispatch much. Spare online capacity is fairly high during midday and nighttime, but it quickly tightens during the peak hours. Approximately $60 \mathrm{GW}$ of CTs are also started around peak in every scenario 


\subsubsection{High Instantaneous VG Penetration}

Between May 11 and May 13, the system experiences one of its highest penetrations of VG. More than $500 \mathrm{GW}$ of wind and PV are available at the peak VG potential, with U.S. Eastern Interconnection load never breaking $400 \mathrm{GW}$.

Figure 25 shows the dispatch for this period. Some real differences between scenarios are evident during these three days. The Base- $70 \%$ and Base- $75 \%$ scenarios take as much flexibility from the thermal fleet as possible, shutting down nearly all of the thermal fleet during the middle of the day. That same flexibility does not exist in the Must Run-70\% and VG Limit-70\% scenarios. This significantly increases VG curtailment, particularly overnight, when wind generation is stable. The Hurdle Rate- $70 \%$ scenario remains similar to the Base scenario, although there are regional differences (not seen here).

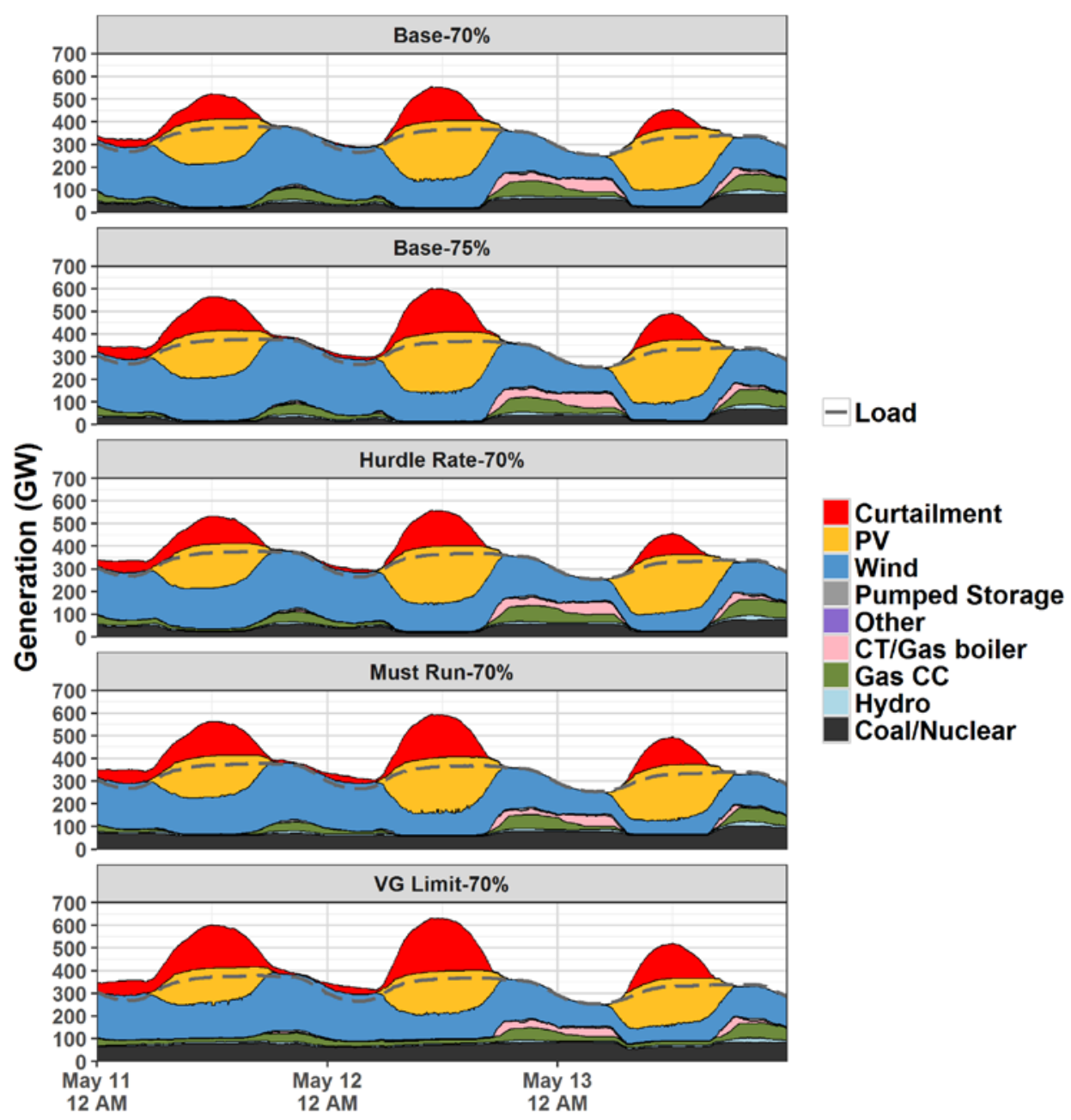

Figure 25. High instantaneous VG penetration period

Figure 26 shows the available capacity and generation plots associated with the high VG period. In the Base-70\% and Base- $75 \%$ scenarios, both the coal and nuclear and combined cycle units are cycled on/off. The combined cycle units are essentially only used for the hours around daily net-load peaks, while the coal and nuclear units are shutoff as they are able, but some capacity 
remains online at all hours. The Base scenarios reach their minimum committed capacity during the day when VG has 500 GW of generation available. Little spare online capacity exists in the combined cycle fleet when they are on, and coal and nuclear units also have little spare online capacity during net-load peak hours. The VG Limit-70\% and Must Run-70\% scenarios maintain more spare online thermal capacity at the cost of increased curtailment. The Hurdle Rate-70\% scenario has more coal and nuclear committed than the Base-70\% and Base-75\% scenarios, but it can turn off more than the VG Limit-70\% and Must Run-70\%.

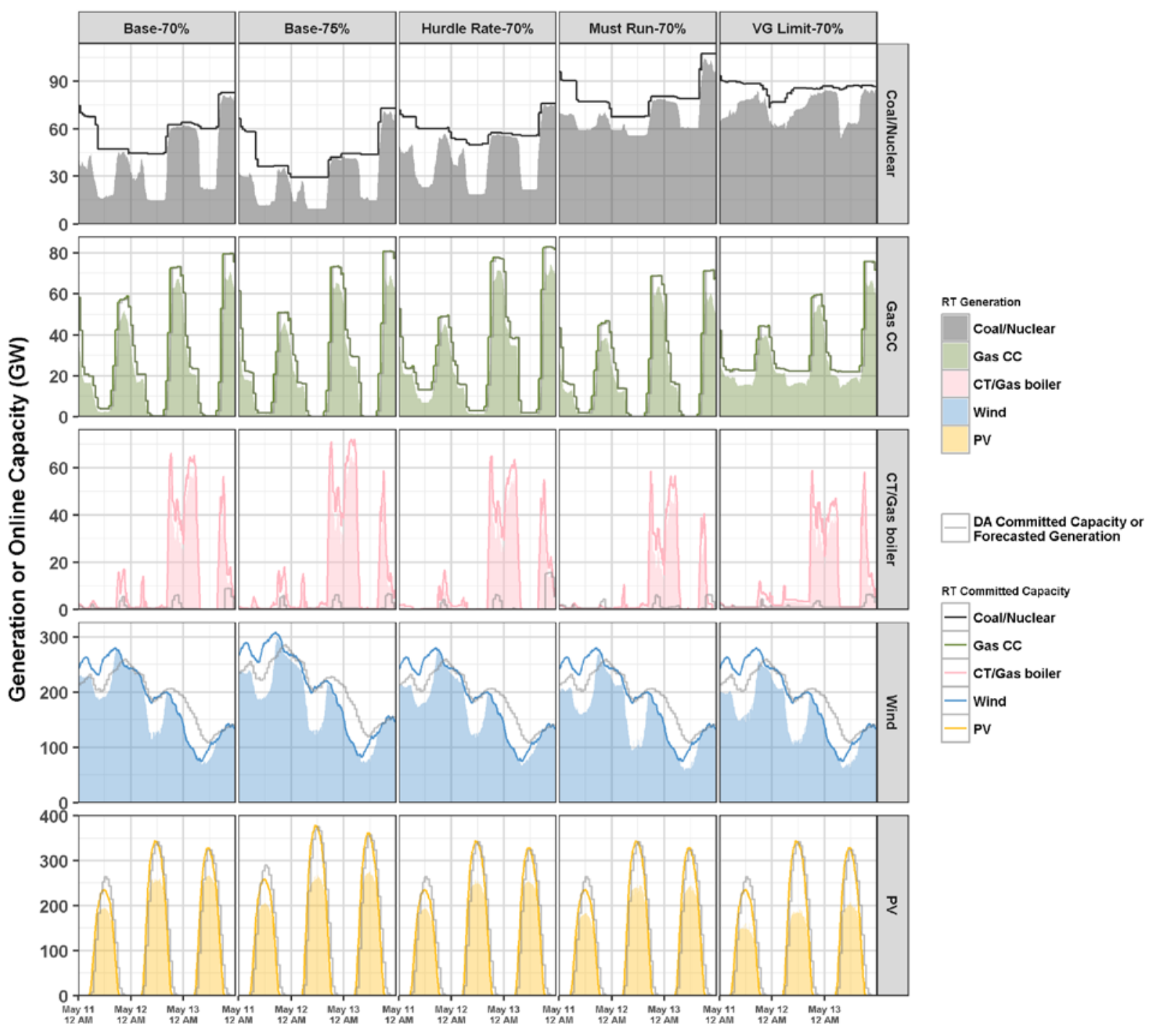

Figure 26. Commitment and dispatch during high instantaneous VG penetration period

A wind forecast error on the evening of the highest VG penetration (May 12), led to a large startup of quick-start generation as the sun begins to set in the Base-70\%, Base-75\%, and Hurdle Rate-70\% scenarios. In both scenarios, combustion turbine and gas boiler generation and online capacity exceeds coal and nuclear generation. Quick-start units are also called on in the VG Limit-70\% and Must Run-70\% scenarios, but they are used less than they are in the Base-70\% and Base- $75 \%$ scenarios, as they have more spare online capacity and more committed coal and nuclear capacity. 


\subsubsection{High Net-Load Ramp}

The high net-load ramp period is similar to the high instantaneous VG period; load is relatively low, and potential VG again reaches $500 \mathrm{GW}$. In this November period, however, a much larger wind forecast error occurs, and it is timed even closer to the ramp down in PV in the evening. Peak load each day also occurs after sunset. This leads to a large ramp up in the net load.

Figure 27 shows the dispatch plot for this period. Unlike the May period, all scenarios react similarly to the system conditions. Curtailment is slightly higher in the less-flexible scenarios (VG Limit-70\% and Must Run-70\%), while CT usage is somewhat larger in the Base-70\% and Base-75\% scenarios.

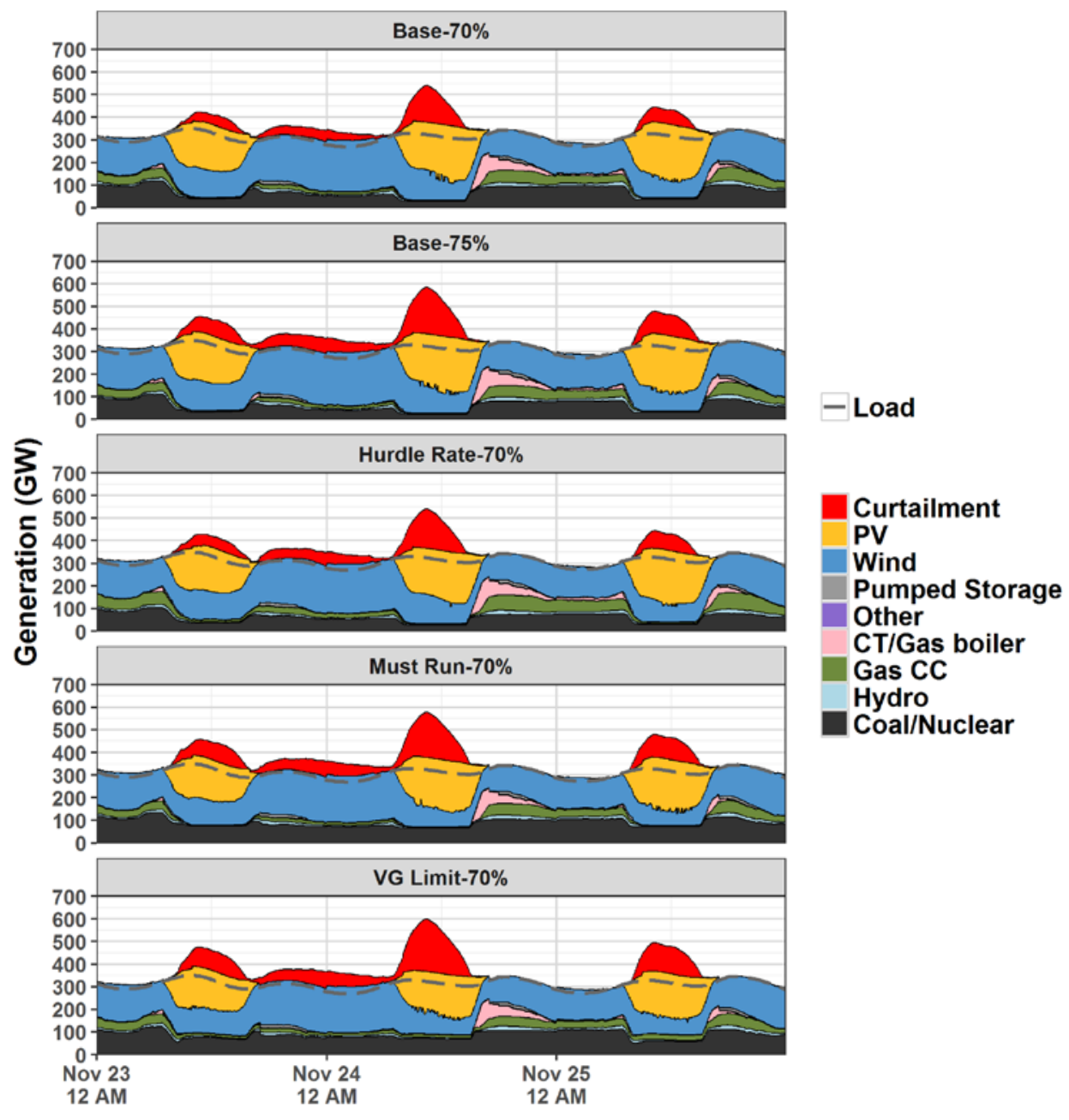

Figure 27. High net-load ramp period

Figure 28 shows available capacity and generation of the system during the high net-load period. Again, system operations are similar across scenarios, with the less-flexible scenarios committing slightly more coal, nuclear, and combined cycle units in the day-ahead, and the more flexible starting up a few more CTs to deal with the net-load ramp on the evening of November 24. 


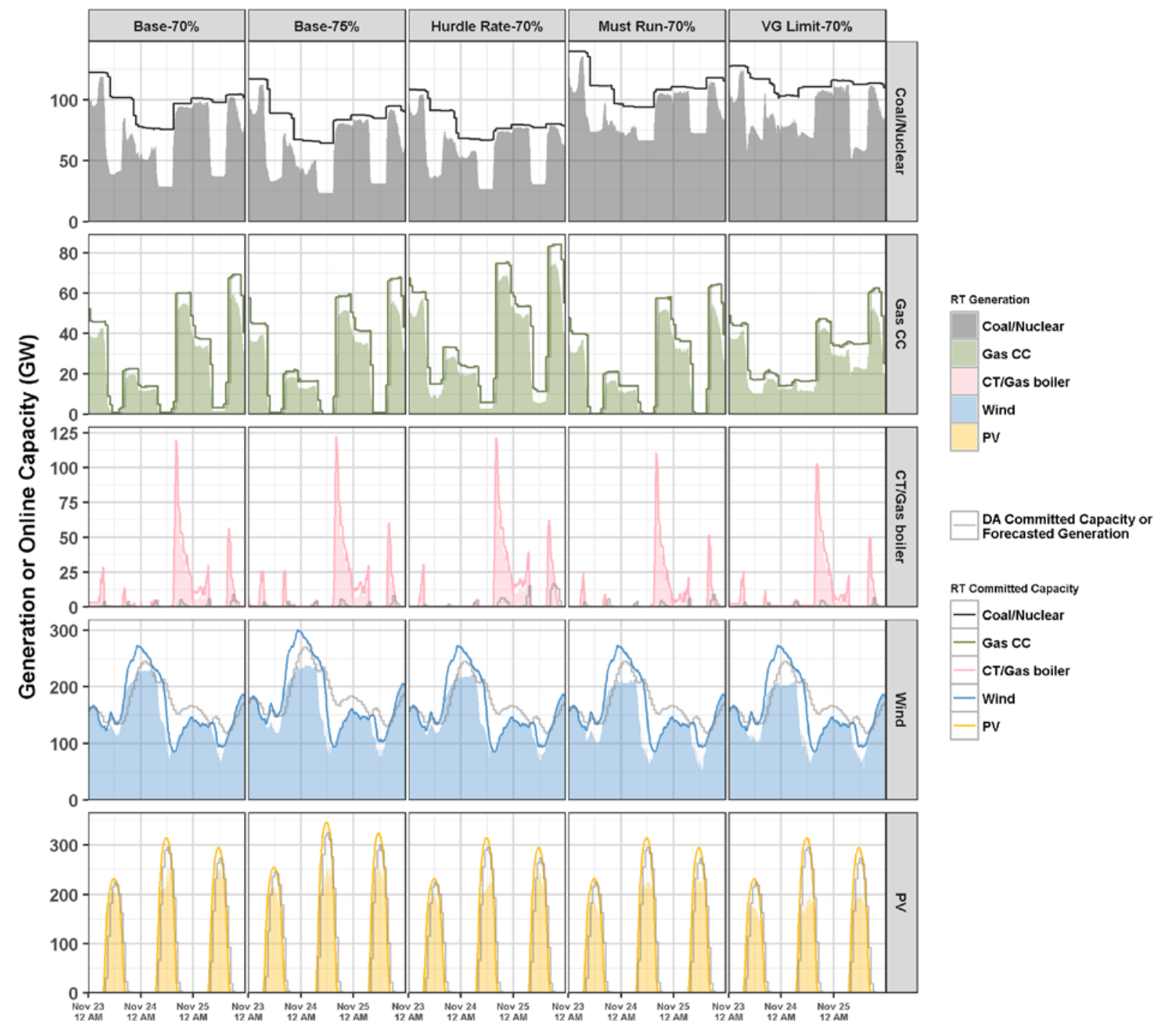

Figure 28. Commitment and dispatch during high net-load period 


\section{Conclusions}

Simulation results from this study indicate that large penetrations of VG added to the U.S. Eastern Interconnection can be balanced at the five-minute level under the scenarios considered and the conditions assumed in those scenarios. Beyond exploring the feasibility of balancing $70 \%-75 \%$ VG, we also investigated system stress, or periods during the year that may be particularly challenging for the economics or operations of the system. From the system stress analysis, we identified tradeoffs from increasing curtailment while decreasing other operational stressors.

The following are key findings from this analysis:

- Balancing 70\%-75\% renewables (68\%-73\% wind and solar) at five-minute levels in the Eastern Interconnection is possible while maintaining $99.99 \%$ of required reserves.

- The model estimated curtailment to be $7 \%-10 \%$ annually, assuming grid operations were flexible.

- Assumed flexibility challenges in grid operations and flexibility at existing thermal generators did not impact the balancing conclusion. However, these challenges caused curtailment to increase to $9 \%-14 \%$ annually, making it more economically challenging to incorporate $70 \%$ renewable generation. These challenges led to $\$ 2$ billion- $\$ 3$ billion per year in additional operating costs, and additional emissions associated with the curtailed clean energy.

- While the flexibility challenges had no effect on the ability of the system to maintain spare online capacity, they led to fewer hours with very high instantaneous penetrations of VG.

- Modest hurdle rates for transmitting power between regions led to a modest increase (7.3\%-8.8\%) in curtailment.

- While curtailment and generation from wind and solar resources were reasonably well predicted in the day-ahead simulation, peaking generation from natural gas combustion turbines was not well predicted, in part due to the assumed lack of intraday reliability commitment. More research is needed to understand how forecasts and intraday commitments can predict usage of peaking generators.

- More research is needed to understand dynamic stability and voltage issues at high VG penetrations, and whether additional constraints or technologies may be necessary to operate these scenarios reliably.

Across all scenarios, many of the peaking generator start-ups occurred because the five-minute net-load deviated from the average hourly net load (to which the day-ahead is scheduled), and much of this deviation is predictable (during sunrise and sunset). Other more targeted operating strategies, such as additional reserve products, stochastic optimization, or subhourly commitment scheduling, could potentially reduce system stress and should be explored in more detail.

More work is also needed to understand the reliability of operation of these scenarios. While this study analyzes curtailment, resource adequacy, transmission availability, and operational stresses 
at these penetrations, an understanding of the dynamic stability of such high variable renewable energy systems is needed, including the implications for frequency support, voltage stability, and other dynamic issues. Similarly, the siting, institutional, economic, wholesale market operations, and other non-technical aspects of these scenarios may need more analysis. 


\section{References}

Barrows, Clayton, Jessica Katz, Jaquelin Cochran, Galen Maclaurin, Mark Christian Marollano, Mary Grace Gabis, Noriel Christopher Reyes, et al. 2018. Greening the Grid: Solar and Wind Grid Integration Study for the Luzon-Visayas System of the Philippines. Golden, CO: National Renewable Energy Laboratory. NREL/TP-6A20-68594. https://www.nrel.gov/docs/fy18osti/68594.pdf.

Barrows, Clayton, Brendan McBennett, Josh Novacheck, Devon Sigler, Jessica Lau, and Aaron Bloom. Submitted. “A Multi-Operator Approach to Unit Commitment and Economic Dispatch Modeling.” Submitted to IEEE Transactions on Power Systems.

Bloom, Aaron, Aaron Townsend, David Palchak, Joshua Novacheck, Jack King, Clayton Barrows, Eduardo Ibanez, et al. 2016. Eastern Renewable Generation Integration Study. Golden, CO: National Renewable Energy Laboratory. NREL/TP-6A20-64472. https://www.nrel.gov/docs/fy16osti/64472.pdf.

Brinkman, Gregory, Jennie Jorgenson, Ali Ehlen, and James H. Caldwell. 2016. Low Carbon Grid Study: Analysis of a 50\% Emission Reduction in California. Golden, CO: National Renewable Energy Laboratory. NREL/TP-6A20-64884. https://www.nrel.gov/docs/fy16osti/64884.pdf.

Cole, Wesley, Trieu Mai, Jeffrey Logan, Daniel Steinberg, James McCall, James Richards, Benjamin Sigrin, and Gian Porro. 2016. 2016 Standard Scenarios Report: A U.S. Electricity Sector Outlook. Golden, CO: National Renewable Energy Laboratory. NREL/TP-6A20-66939. https://www.nrel.gov/docs/fy17osti/66939.pdf.

Cole, Trieu Mai, Paul Donohoo-Vallett, James Richards, and Paritosh Das. 2017. 2017 Standard Scenarios Report: A U.S. Electricity Sector Outlook. Golden, CO: National Renewable Energy Laboratory. NREL/TP-6A20-68548. https://www.nrel.gov/docs/fy18osti/68548.pdf.

Denholm, Paul, Matthew O’Connell, Gregory Brinkman, and Jennie Jorgenson. 2015. Overgeneration from Solar Energy in California: A Field Guide to the Duck Chart. Golden, CO: National Renewable Energy Laboratory. NREL/TP-6A20-65023. https://www.nrel.gov/docs/fy16osti/65023.pdf.

DNV GL. 2014. Integrating Renewable Energy in Europe. Bonn, Germany: DNV GL. 9011-700. https://ec.europa.eu/energy/sites/ener/files/documents/201406_report_renewables_integration_eu rope.pdf.

Heard, B. P., B. W. Brook, T. M. L. Wigley, and C. J. A. Bradshaw. 2017. "Burden of Proof: A Comprehensive Review of the Feasibility of 100\% Renewable-Electricity Systems." Renewable and Sustainable Energy Reviews 76(September): 1122-1133. https://doi.org/10.1016/j.rser.2017.03.114.

Liu, Shucheng. 2014. "Direct Testimony of Dr. Shucheng Liu on Behalf of the California Independent System Operator Corporation.” Rulemaking 13-12-010 for California Public Utilities Commission. 
MacDonald, Alexander E., Christopher T. M. Clack, Anneliese Alexander, Adam Dunbar, James Wilczak, and Yuanfu Xie. 2016. "Future Cost-Competitive Electricity Systems and Their Impact on US CO2 Emissions.” Nature Climate Change 6(5): 526-531.

https://doi.org/10.1038/nclimate2921.

Mai, T., R. Wiser, D. Sandor, G. Brinkman, G. Heath, P. Denholm, D.J. Hostick, N. Darghouth, A. Schlosser, and K. Strzepek. 2012. Renewable Electricity Futures Study. Volume 1: Exploration of High-Penetration Renewable Electricity Futures. (Volume 1 of 4). NREL/TP6A20-52409-1. https://www.nrel.gov/docs/fy12osti/52409-1.pdf.

Miller, Nicholas W., M. Shao, S. Pajic, and R. D’Aquila. 2014. Western Wind and Solar Integration Study Phase 3: Frequency Response and Transient Stability. Golden, CO: National Renewable Energy Laboratory. NREL/SR-5D00-62906.

https://www.nrel.gov/docs/fy15osti/62906.pdf.

Nelson, James H., and Laura M. Wisland. 2015. Achieving 50 Percent Renewable Electricity in California. Union of Concerned Scientists.

https://www.ucsusa.org/sites/default/files/attach/2015/08/Achieving-50-Percent-RenewableElectricity-In-California.pdf.

Schlag, Nick, Arne Olson, Elaine Hart, Ana Mileva, Ryan Jones, Carlo Brancucci MartinezAnido, Bri-Mathias Hodge, et al. 2015. Western Interconnection Flexibility Assessment. San Francisco, CA: Energy and Environmental Economics, Inc. https://www.wecc.biz/Reliability/WECC_Flexibility_Assessment_Report_2016-01-11.pdf.

Stoll, Brady, Gregory Brinkman, Aaron Townsend, and Aaron Bloom. 2016. Analysis of Modeling Assumptions used in Production Cost Models for Renewable Integration Studies. Golden, CO: National Renewable Energy Laboratory. NREL/TP-6A20-65383. https://www.nrel.gov/docs/fy16osti/65383.pdf. 